\title{
Banks Increase Welfare
}

\author{
BY MARgARITA SAMARTÍN
}

\begin{abstract}
This paper examines the relative degrees of risk sharing provided by demand deposit contracts and equity contracts. It is shown that in a framework in which individuals have smooth preferences and there exists some type of aggregate uncertainty (interest rate risk), the allocations obtained with a financial intermediary allow in general for greater risk sharing than those achieved in an equity economy. However, the interest rate is essential in order to determine the superiority of demand deposit contracts over equity contracts. The results of the paper contradict the ones obtained by Jacklin [1987] and Hellwig [1994], where demand deposit and equity contracts are always equivalent risk sharing instruments.
\end{abstract}

\section{INTRODUCTION}

Modern financial intermediation literature has focused on modeling bank runs and on measures to prevent them (see Bryant [1980] or Diamond and Dybvig [1983] among others). The key feature of these models is that financial intermediaries, by issuing demand deposits, provide insurance to individuals that are uncertain about their liquidity needs. However, the demand deposit contract, providing this risk sharing, has an undesirable equilibrium (a bank run), in which all depositors withdraw immediately. Bank runs cause real economic problems and can be prevented with different intervention measures.

Although the focus of the above papers was bank runs, they also identified the demand deposit as a vehicle that facilitates risk sharing. Building on this idea, another branch of literature has analyzed the different degrees of risk sharing provided by demand deposits and traded equity contracts ${ }^{1}$ (see Jacklin [1987], Jacklin [1993], Hellwig [1994] and Jacklin and Bhattacharya [1988]²). The purpose of these papers is to see whether financial intermediaries have a positive role in the economy, by ensuring liquidity needs, or on the contrary,

${ }^{1}$ Traded equity contracts refer to the allocations achieved in a Walrasian market in which individuals hold the assets directly.

${ }^{2}$ These models of intertemporal liquidity risk have been recently extended to compare banks versus markets, in a dynamic framework (see Fulghieri and Rovelli [1999], Dutta and Kapur [1994], Bhattacharya and Padilla [1996] and Bhattacharya, Fulghieri and Rovelli [1998] as examples of such work). 
these same services can be provided by other non-financial intermediaries without the risk of bank runs.

As Jacklin [1987] noted, the Diamond-Dybvig specification, with corner preferences, riskless assets and no aggregate uncertainty, has the feature that demand deposit and equity contracts provide the same risk sharing opportunities. This rules out a positive role for a financial intermediary in the economy. Hellwig [1994] confirms this result in a model similar to the Diamond-Dybvig one, but in which there exists a stochastic technology between dates 1 and 2, interpreted as technology-induced interest rate risk. This risk poses an important problem for all financial institutions which, in order to create liquidity, take in short term deposits and invest in long term assets. The paper focuses on how interest rate risk should be shared among agents in the economy and how it is related with the provision of liquidity. In a later paper, Jacklin [1993] shows that unless there is both aggregate uncertainty about preferences and banks assets are risky, with depositors asymmetrically informed about asset quality, then traded equity contracts again provide the same services as demand deposit contracts, without the possibility of panics. The message of his paper is that liquidity transformation can and should be provided using equity contracts where the underlying assets may or not be risky, but where there is little or no potential for asymmetries of information about asset quality. The above papers considered models in which individuals have corner utility functions, that are not considered a realistic characterization of individuals' preferences. With smooth preferences and no aggregate uncertainty, Jacklin [1987] has shown that non traded demand deposit contracts and traded equity are not welfare equivalent. In fact, demand deposits are shown to provide greater risk sharing than equity shares. Jacklin and Bhattacharya [1988] also considered the relative degree of risk sharing provided by traded and non traded contracts, in a framework in which bank assets are risky, and individuals (with smooth preferences) are informed about bank asset quality. The basic result is that deposit contracts tend to be better for financing low risk assets. However, neither of the two models considers interest rate risk.

This paper intends to cover one gap in this recent theory. It considers a framework in which individuals have smooth preferences and in which there is a random short term investment opportunity from date 1 to date 2, which is interpreted as interest rate risk (as in Hellwig [1994]). The paper shows that in this more general framework, demand deposits allow for greater risk sharing than traded equity, if the interest rate is below a limit value. Otherwise, both solutions coincide. This limit value depends on the level of risk aversion in the population, the long and short term asset returns.

The structure of the paper is as follows: The basic framework of the model is presented in Section II. This section characterizes the efficient allocation of interest rate risk and its interdependence with liquidity provision, under different information assumptions. As shown by Jacklin [1987], the demand deposit contract can be used to achieve the social optimum constrained by incentive 
compatibility. Section III compares the second best allocation (demand deposit contract or non traded solution) with the allocations achieved in an equity economy in which individuals hold the assets directly (traded solution). An analytical example is provided in Section IV. Section V concludes the paper.

\section{DESCRIPTION OF THE MODEL}

There is an economy going through a sequence of three periods $(T=0,1,2)$, and one good per period, which may be used for investment as well as consumption. There are three investment opportunities:

- A short term asset at $T=0$ that yields a sure return $b_{o 1}$ at $T=1$.

- A long term asset at $T=0$ that yields a sure return $b_{o 2}$ at $T=2$, premature liquidation of the asset is feasible but the rate of return is only $b_{1}<b_{o 1}$.

- A short term asset at $T=1$ that yields a random return $\tilde{b}_{12} \geq 1$ at $T=2$. The random variable is known at $T=1$. At $T=0$, only the probability distribution is known. ${ }^{3}$

On the household side of the economy, there is a continuum of unit mass of ex ante identical consumers. These individuals are endowed with one unit of the consumption good at $T=0$ and are uncertain about their future time preferences. They are subject at $T=1$ to a privately observed uninsurable risk of being of type 1 with probability $t$ or of type 2 with probability $1-t$.

Their preferences will be represented by an additive utility function which is of the form:

$$
U^{i}\left(c_{1 i}, c_{2 i}, \rho_{i}\right)=\rho_{i} \frac{c_{1 i}^{1-\gamma}}{1-\gamma}+\left(1-\rho_{i}\right) \frac{c_{2 i}^{1-\gamma}}{1-\gamma}
$$

where: $0 \leq \rho_{2} \leq \rho_{1} \leq 1, i=1,2$ (type), and $\gamma>1$.

It is assumed a more general preference structure with respect to Hellwig [1994] as individuals derive utility from consumption in both periods, with type 1 agents deriving relatively more utility from consumption in the first period with respect to type 2 agents.

It is also assumed no aggregate uncertainty, so that with probability one a fraction $t$ of consumers are of type 1 and a fraction $1-t$ of type 2 .

Finally, it is assumed $b_{1} \tilde{b}_{12}<b_{o 2}$, for each possible realization of $\tilde{b}_{12}$, that is, at date 1 it is never desirable to liquidate the long term investment in order to make room for new short term ones.

\footnotetext{
${ }^{3}$ For simplicity, a triangular distribution for the random return is assumed. The use of this distribution, defined by its mean and standard deviation, does not affect the qualitative nature of the results with respect to Hellwig.
} 
The economy must deal with the following allocation problem:

- At $T=0$ the initial endowment must be divided between short and long term investments $\left(k_{o}=k_{o 1}+k_{o 2}\right)$

- At $T=1$ the fraction $(0 \leq \mu \leq 1)$ of the long term investment that is liquidated must be determined, this may depend on the observed value of $\tilde{b}_{12}$.

- At $T=1$ the returns from short term assets and possibly liquidated long term investments must be divided between consumption and new short term investments, this may also depend on the observed realization of $\tilde{b}_{12}$.

This random short term return $\left(\tilde{b}_{12}\right)$ can be interpreted as technologyinduced interest rate risk, and is considered an important source of risk in an economy (see Hellwig [1994] for a discussion of the problem of interest rate risk). This random return plays a crucial role in characterizing the optimal allocation. As already mentioned in the introduction, this paper characterizes the efficient allocation of interest rate risk and its interdependence with the provision of liquidity. This efficient allocation can be implemented by a financial intermediary, using a demand deposit contract. The purpose of the paper is to see whether in this framework the demand deposit allows for greater risk sharing than the allocations achieved in an equity economy. As a benchmark case, the complete information situation is studied first.

\section{First Best Allocations Under COMPLete Information}

In the complete information case, it is assumed the type of the consumer is publicly observable and in this situation the efficient allocation will be the solution to the following problem:

$$
\max _{\tilde{c}_{i j}, k_{01}, k_{02}, \tilde{\mu}} E\left[t U\left(\tilde{c}_{11}, \tilde{c}_{21}, \rho_{1}\right)+(1-t) U\left(\tilde{c}_{12}, \tilde{c}_{22}, \rho_{2}\right)\right]
$$

$$
\begin{array}{ll}
\text { s.t. } & k_{o 1}+k_{o 2}=k_{o}=1 \\
& \tilde{c}_{11}+(1-t) \tilde{c}_{12} \leq b_{o 1} k_{o 1}+b_{1} \tilde{\mu} k_{o 2} \\
& t \tilde{c}_{21}+(1-t) \tilde{c}_{22}=b_{o 2}(1-\tilde{\mu}) k_{o 2}+\tilde{b}_{12}\left[b_{o 1} k_{o 1}+b_{1} \tilde{\mu} k_{o 2}-t \tilde{c}_{11}-(1-t) \tilde{c}_{12}\right] \\
& \tilde{\mu} \leq 1 \\
& \tilde{c}_{i j} \geq 0 \\
& \tilde{\mu} \geq 0 \\
& k_{o 1} \geq 0 \\
& k_{o 2} \geq 0
\end{array}
$$


The utility function is the one described in equation [1]. $\tilde{c}_{11}, \tilde{c}_{21}$ represents the prior plan indicating the consumption bundle allocated to type 1 consumers and $\tilde{c}_{12}, \tilde{c}_{22}$ the plan allocated to type 2 consumers. The feasibility constraints are the second and third constraints respectively. The second one requires that aggregate consumption at $T=1$ should be less or equal to aggregate resources per capita available from short term investments and possibly liquidated long term ones. Similarly, the third constraint requires that aggregate consumption at $T=2$ should be covered by non liquidated long term investments plus short term re-investments of unused resources at $T=1{ }^{4}$

This maximization problem is solved as a two-step problem:

- In a first step, the initial investment choices, $\left(k_{o 1}, k_{o 2}\right)$ are considered as exogenous parameters and the optimal consumption levels and liquidation policy are determined.

- In a second step the indirect utility function derived in the first step is maximized on $k_{o 1}$ and $k_{o 2}$, and so the optimal levels of the initial investments are obtained.

The solution to the first best problem gives the main result of the section, expressed by the following proposition:

Proposition 1: Let $\left(k_{o 1}^{*}, k_{o 2}^{*}, c_{11}^{*}, c_{12}^{*}, c_{21}^{*}, c_{22}^{*}, \mu^{*}\right)$ be a solution to the first best problem and define:

$$
b_{\lim }=\left\{\frac{b_{o 1} k_{o 1}\left[t+(1-t)\left(\frac{\rho_{2}}{\rho_{1}}\right)^{-1 / \gamma}\right]}{b_{o 2} k_{o 2}\left[t+(1-t)\left(\frac{\rho_{1}}{\rho_{2}}\right)^{-1 / \gamma}\right]}\right\}^{-\gamma} \frac{\rho_{1}}{1-\rho_{1}}
$$

if $\tilde{b}_{12}<b_{\text {lim }}:$ CASE A

$$
\begin{array}{ll}
\tilde{c}_{11}^{*}=\frac{b_{o 1} k_{o 1}}{t+(1-t)\left[\frac{\rho_{1}}{\rho_{2}}\right]^{-1 / \gamma}} & \tilde{c}_{21}^{*}=\frac{b_{o 2} k_{o 2}}{t+(1-t)\left[\frac{\rho_{2}}{\rho_{1}}\right]^{-1 / \gamma}} \\
\tilde{c}_{12}^{*}=\left[\frac{\rho_{1}}{\rho_{2}}\right]^{-1 / \gamma} \tilde{c}_{11}^{*} & \tilde{c}_{22}^{*}=\left[\frac{\rho_{2}}{\rho_{1}}\right]^{-1 / \gamma} \tilde{c}_{21}^{*}
\end{array}
$$

\footnotetext{
${ }^{4}$ Given the observed realization of the short term return, $\tilde{b}_{12}$, the decision between consumption and re-investment in this new short term asset takes place. If there is no reinvestment, the first resource constraint would be satisfied as an equality. The constraints would then become:
}

$$
\begin{aligned}
& t \tilde{c}_{11}+(1-t) \tilde{c}_{12}=b_{o 1} k_{o 1}+b_{1} \tilde{\mu} k_{o 2} \\
& t \tilde{c}_{21}+(1-t) \tilde{c}_{22}=b_{o 2}(1-\tilde{\mu}) k_{o 2}
\end{aligned}
$$


if $\tilde{b}_{12} \geq b_{\text {lim }}:$ CASE B

$$
\begin{gathered}
\tilde{c}_{12}^{*}=\left[\frac{\rho_{1}}{\rho_{2}}\right]^{-1 / \gamma} \tilde{c}_{11}^{*} \tilde{c}_{11}^{*}=\left[\frac{\rho_{2}}{\rho_{1}} \tilde{b}_{12}\right]^{-1 / \gamma} \tilde{c}_{21}^{*} \\
\tilde{c}_{21}^{*}=\frac{b_{o 1} k_{o 1} \tilde{b}_{12}+b_{o 2} k_{o 2}}{t\left[1+\left(\frac{\rho_{2}}{\rho_{1}}\right)^{-1 / \gamma}+\tilde{b}_{12}^{\frac{\gamma-1}{\gamma}}\right]+(1-t)\left[\left(\frac{\rho_{2}}{\rho_{1}}\right)^{-1 / \gamma}+b_{12}^{\frac{\gamma-1}{\gamma}}\right]} \quad \tilde{c}_{22}^{*}=\left[\frac{\rho_{2}}{\rho_{1}}\right]^{-1 / \gamma} \tilde{c}_{21}^{*}
\end{gathered}
$$

and $\mu^{*}=0$.

Proof: See Appendix A.

Given that $k_{o 1}$ is an endogenous variable, this characterization may seem awkward, but it is understood in terms of dynamic programming considerations. As mentioned before, the maximization problem given by equations [2] and [3] has been solved as a two step problem: In the first step, $k_{o 1}$ and $k_{o 2}$ were considered as exogenous parameters and the optimal consumption levels were obtained. In the second step, the optimal levels of the initial investments were derived, maximizing on $k_{o 1}$ and $k_{o 2}$ the indirect utility function of the first step problem, that is, the optimal levels of $k_{o 1}$ and $k_{o 2}$ are obtained as a solution to the following problem:

$$
\begin{aligned}
& \max _{k_{o 1}, k_{o 2}}\left[\int_{b_{\min }}^{b_{\lim }} U^{*(A)} f\left(b_{12}\right) d b_{12}+\int_{b_{\lim }}^{b_{\max }} U^{*(B)} f\left(b_{12)} d b_{12}\right]\right. \\
& \text { s.t: } k_{o 1}+k_{o 2}=k_{o}
\end{aligned}
$$

The consumption levels are the ones specified in Proposition 1. It is observed that for low values of the random return, and up to a limit value $\left(b_{\lim }\right)$, consumption is independent of $\tilde{b}_{12}$, but once this limit value is achieved, consumption depends on the random return: first period consumption decreases, second period consumption increases with $\tilde{b}_{12}$. In mathematical terms, this means that for low values of the random return, the first resource constraint is binding, and therefore consumption is constant, and once the limit value is attained, the constraint is no longer binding, and therefore consumption depends on $\tilde{b}_{12}$. The intuition for this result is that given the high value of the random return, it becomes advantageous to reinvest some of the return available from the short term asset at $T=1\left(b_{o 1} k_{o 1}\right)$, in the new short term technology. From an ex ante point of view, the uncertainty about the random return is seen as a source of opportunities rather than a threat. The optimal allocation implies reducing consumption of individuals at date 1 and increasing it at date 2, in order to take advantage of the high return. While long term investments are earmarked for consumption 


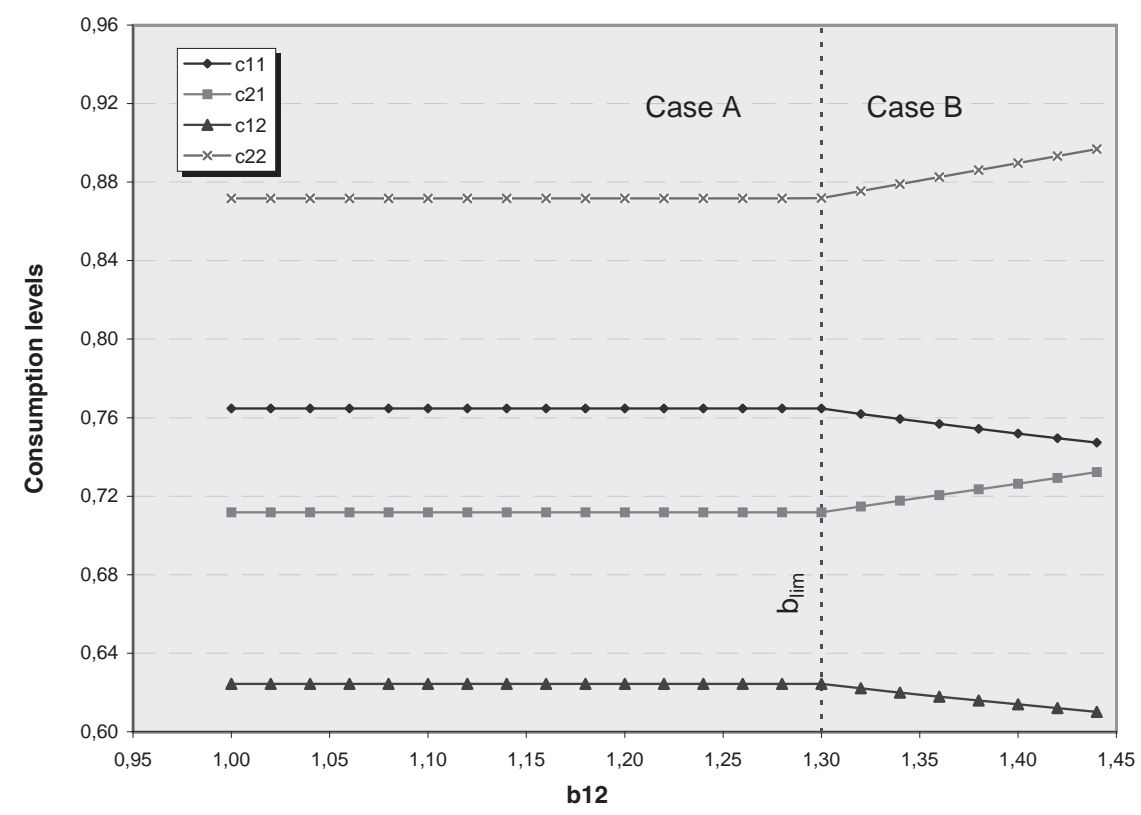

Figure 1: Optimal consumption levels in the first best allocation

at date 2, short term investments are not necessarily earmarked for consumption at date 1 , and therefore, the choice between consumption and investment depends on the rate of return $\tilde{b}_{12}$ on the new short term investments.

Finally, given the condition $b_{1}<b_{o 1}$, it can be easily shown that liquidation of the long term investment is always zero in the first best allocation $\left(\mu^{*}=0\right)$.

\section{Numerical Simulations}

Figure 1 shows the optimal consumption levels, in the first best case. The data used in the simulations are given in Table 1. The graph plots consumption for type $1\left(\tilde{c}_{11}, \tilde{c}_{21}\right)$ and type $2\left(\tilde{c}_{12}, \tilde{c}_{22}\right)$ agents for different values of the random return. It is observed that as interest rate increases, first period consumption decreases, and second period consumption increases.

Table 1: Input data for the numerical simulations for Figure 1 to Figure 7.

\begin{tabular}{cccccccc}
\hline$t$ & $\rho_{1}$ & $\rho_{2}$ & $\gamma$ & $b_{o 1}$ & $b_{o 2}$ & $b_{1}$ & $E b_{12}, \sigma$ \\
\hline 0.50 & 0.60 & 0.40 & 2.00 & 1.30 & 1.70 & 1.00 & $1.22-0.05$ \\
\hline
\end{tabular}




\section{SECOND Best Allocations under InCOMPLETE INFORMATION}

In this case it is assumed that the realization of the timing of the consumption needs is private information of the consumer. Given this information asymmetry, an allocation can only be implemented if it is incentive compatible, that is, if it gives no consumer an incentive to lie or deviate about what he actually wants to consume. In the case of a type 2 agent, incentive compatibility requires that the utility obtained from the consumption bundle he receives if he is honest $\left(\tilde{c}_{12}, \tilde{c}_{22}\right)$, should be at least as large as the utility obtained by lying and behaving like a type 1 agent, that is, obtaining the consumption bundle $\left(\tilde{c}_{11}, \tilde{c}_{21}\right)$ and then reinvesting his first period consumption in the backyard technology in the optimal way for him. If he reinvested part of his first period allocation $\left(\tilde{c}_{11}\right)$ in the new short term asset, his optimal consumption levels in both periods $\tilde{c}_{1}^{*}, \tilde{c}_{2}^{*}$ are the solution to the following problem:

$$
\begin{gathered}
\max _{\tilde{c}_{1}, \tilde{c}_{2}}\left\{\rho_{2} \frac{\tilde{c}_{1}^{1-\gamma}}{1-\gamma}+\left(1-\rho_{2}\right) \frac{\tilde{c}_{2}^{1-\gamma}}{1-\gamma}\right\} \\
\text { s.t } \tilde{c}_{1} \leq \tilde{c}_{11} \\
\tilde{c}_{2}=\left(\tilde{c}_{11}-\tilde{c}_{1}\right) \tilde{b}_{12}+\tilde{c}_{21}
\end{gathered}
$$

which yields:

$$
\tilde{c}_{1}^{*(2)}=\left[\left(\frac{1-\rho_{2}}{\rho_{2}}\right) \tilde{b}_{12}\right]^{-1 / \gamma} \tilde{c}_{2}^{*} \leq \tilde{c}_{11} \quad \tilde{c}_{2}^{*(2)}=\frac{\tilde{c}_{21}+\tilde{c}_{11} \tilde{b}_{12}}{1+\tilde{b}_{12}^{\frac{\gamma-1}{\gamma}}\left(\frac{1-\rho_{2}}{\rho_{2}}\right)^{-1 / \gamma}}
$$

The incentive compatibility constraint for a type- 2 agent is then:

$$
\rho_{2} \frac{\tilde{c}_{12}^{1-\gamma}}{1-\gamma}+\left(1-\rho_{2}\right) \frac{\tilde{c}_{22}^{1-\gamma}}{1-\gamma} \geq \rho_{2} \frac{c_{1}^{*(2)^{1-\gamma}}}{1-\gamma}+\left(1-\rho_{2}\right) \frac{c_{2}^{*(2)^{1-\gamma}}}{1-\gamma}
$$

The incentive constraint for a type- 1 agent is obtained in a similar way, and would be:

$$
\rho_{1} \frac{\tilde{c}_{11}^{1-\gamma}}{1-\gamma}+\left(1-\rho_{1}\right) \frac{\tilde{c}_{21}^{1-\gamma}}{1-\gamma} \geq \rho_{1} \frac{c_{1}^{*(1)^{1-\gamma}}}{1-\gamma}+\left(1-\rho_{1}\right) \frac{c_{2}^{*(1)^{1-\gamma}}}{1-\gamma}
$$

where:

$$
\tilde{c}_{1}^{*(1)}=\left[\left(\frac{1-\rho_{1}}{\rho_{1}}\right) \tilde{b}_{12}\right]^{-1 / \gamma} \tilde{c}_{2}^{*} \leq \tilde{c}_{12} ; \quad \tilde{c}_{2}^{*(1)}=\frac{\tilde{c}_{22}+\tilde{c}_{12} \tilde{b}_{12}}{1+\tilde{b}_{12}^{\frac{\gamma-1}{\gamma}}\left(\frac{1-\rho_{1}}{\rho_{1}}\right)^{-1 / \gamma}}
$$

In deriving these incentive compatibility constraints, it is assumed (as in Hellwig [1994]) that they are specified as purely technology-based constraints, 
and without individuals having access to some set of markets on which they can trade among them. ${ }^{5}$ Taking the incentive constraints into account, the second best problem is a solution to the following one:

$$
\begin{array}{ll} 
& \max _{\tilde{c}_{i j}, k_{o 1}, k_{o 2}, \tilde{\mu}} E\left[t U\left(\tilde{c}_{11}, \tilde{c}_{21}, \rho_{1}\right)+(1-t) U\left(\tilde{c}_{12}, \tilde{c}_{22}, \rho_{2}\right)\right] \\
\text { s.t } \quad & k_{o 1}+k_{o 2}=k_{o}=1 \\
& t \tilde{c}_{11}+(1-t) \tilde{c}_{12} \leq b_{o 1} k_{o 1}+b_{1} \tilde{\mu} k_{o 2} \\
& t \tilde{c}_{21}+(1-t) \tilde{c}_{22}=b_{o 2}(1-\tilde{\mu}) k_{o 2}+\tilde{b}_{12}\left[b_{o 1} k_{o 1}+b_{1} \tilde{\mu} k_{o 2}-t \tilde{c}_{11}(1-t) \tilde{c}_{12}\right] \\
& \tilde{\mu} \leq 1 \\
& \tilde{c}_{i j} \geq 0 \\
& \tilde{\mu} \geq 0 \\
& k_{o 1} \geq 0 \\
& k_{o 2} \geq 0
\end{array}
$$

I.C. Constraints

\section{Numerical Simulations}

The analytical treatment of the second best solution is quite a tedious one, therefore numerical solutions have been computed, for the data shown in Table $1 .^{6}$ As in the first best case, the problem is solved in two steps. A graphical plot of the optimal solution is given by Figure 2. As in the first best case, the random return plays a crucial role in characterizing the second best solution: first period consumption decreases and second period consumption increases with the random return. For values of the random return below a specific value $b_{2}$ there is no re-investment of resources at date 1 , and once this critical value is attained it becomes advantegous to reinvest some of the return available at date 1 in the new short term asset. However, in the second best case, a dependence of first period consumption on $\tilde{b}_{12}$ may be imposed by the incentive compatibility constraints. In this sensse, it should be mentioned, that in the optimal solution the incentive constraint for type- 1 agents is never binding and that of type-2 may be binding. ${ }^{7}$

${ }^{5}$ See Section III for a discussion of the coexistence of banks and markets.

${ }^{6}$ The FOCS to this problem are shown in Appendix B. These system of non-linear equations was solved by the Newton Raphson technique, with the use of a computer program, that was written in MSDos Qbasic.

${ }^{7}$ For values of the random return below $b_{1}$ neither of the constraints bind (case A1) and consumption is constant. For values of the random return above $b_{1}$ the incentive constraint for type 2 agents is binding (cases A2 and B) and consumption will depend on the random return. It should be mentioned that as in Hellwig's case a value of $\gamma>1$ ensures that the constraint for type 2 agents binds. 


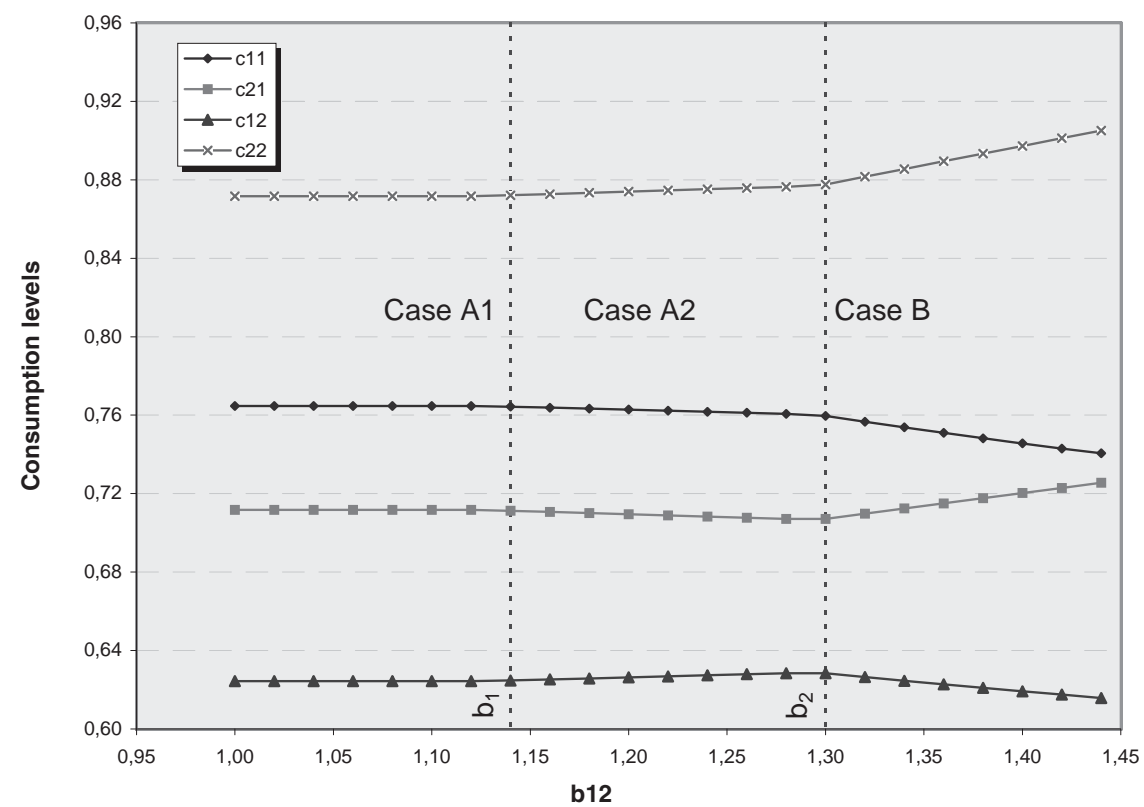

\begin{tabular}{|r|l|c|c|c|c|}
\hline $\mathrm{b}_{12}$ & case & $\mathrm{C}_{11}$ & $\mathrm{C}_{21}$ & $\mathrm{C}_{12}$ & $\mathrm{C}_{22}$ \\
\hline 1,00 & case A1 & 0,76473 & 0,71175 & 0,62440 & 0,87171 \\
1,02 & case A1 & 0,76473 & 0,71175 & 0,62440 & 0,87171 \\
1,04 & case A1 & 0,76473 & 0,71175 & 0,62440 & 0,87171 \\
1,06 & case A1 & 0,76473 & 0,71175 & 0,62440 & 0,87171 \\
1,08 & case A1 & 0,76473 & 0,71175 & 0,62440 & 0,87171 \\
1,10 & case A1 & 0,76473 & 0,71175 & 0,62440 & 0,87171 \\
1,12 & case A1 & 0,76473 & 0,71175 & 0,62440 & 0,87171 \\
\hline 1,14 & case A2 & 0,76436 & 0,71131 & 0,62476 & 0,87215 \\
1,16 & case A2 & 0,76386 & 0,71071 & 0,62526 & 0,87275 \\
1,18 & case A2 & 0,76334 & 0,71011 & 0,62578 & 0,87335 \\
1,20 & case A2 & 0,76282 & 0,70950 & 0,62630 & 0,87395 \\
1,22 & case A2 & 0,76229 & 0,70890 & 0,62683 & 0,87456 \\
1,24 & case A2 & 0,76176 & 0,70830 & 0,62736 & 0,87516 \\
1,26 & case A2 & 0,76122 & 0,70770 & 0,62791 & 0,87576 \\
1,28 & case A2 & 0,76067 & 0,70710 & 0,62845 & 0,87635 \\
\hline 1,30 & case B & 0,75961 & 0,70716 & 0,62848 & 0,87763 \\
1,32 & case B & 0,75664 & 0,70979 & 0,62650 & 0,88157 \\
1,34 & case B & 0,75375 & 0,71242 & 0,62458 & 0,88550 \\
1,36 & case B & 0,75095 & 0,71504 & 0,62272 & 0,88943 \\
1,38 & case B & 0,74822 & 0,71767 & 0,62092 & 0,89335 \\
1,40 & case B & 0,74558 & 0,72030 & 0,61917 & 0,89727 \\
1,42 & case B & 0,74301 & 0,72293 & 0,61748 & 0,90118 \\
1,44 & case B & 0,74052 & 0,72555 & 0,61584 & 0,90509 \\
\hline
\end{tabular}

Figure 2: Optimal Consumption Levels in the Second Best Allocation

A financial intermediary could implement the efficient allocation using a demand deposit contract. Liquidity provision in this case would imply that the optimal rate of deposits withdrawn at date 1 should decrease and those that remain until date 2 should increase. 
Finally, it should be mentioned that for the parameter values of the analysis, there is never liquidation of the long term technology ${ }^{8}$ and that the optimal levels of the initial investments are derived as in the first best case.

\section{COMPARISON WITH AN EQUITY ECONOMY}

As mentioned in the introduction, financial institutions provide liquidity, by transforming illiquid assets into liquid deposits. This gives a role for financial intermediaries in the economy, although it leaves them vulnerable to bank runs. The aim of this section is to compare the level of risk sharing achieved with a demand deposit (ex ante expected utility of the second best allocation calculated in the previous section) and the level that could be obtained in a competitive market. Let an equity contract be defined as a contract that for each unit invested at $T=0$ returns a two period dividend stream $b_{o 1} k_{o 1}$ at $T=1$ and $b_{o 2} k_{o 2}$ at $T=2$. Implicit in this definition is the existence of a market in exdividend claims at $T=1$. Suppose that at $T=1$, there was a Walrasian market for date 1 and date 2 consumption goods and let $R_{2}=1+r$ be some equilibrium interest rate at which individuals are willing to trade good 1 in exchange for good 2, and so that for any agent $j$, his first period consumption will be the amount of the date 1 endowment $\left(b_{o 1} k_{o 1}\right)$ plus the quantity demanded (or supplied) of good 1 in exchange for good 2, and similarly, in the second period, his consumption will be the second period endowment $\left(b_{o 2} k_{o 2}\right)$ plus the quantity supplied (or demanded) of good 2 in exchange for good 1 . That is:

$$
\begin{aligned}
& c_{1 j}=b_{o 1} k_{o 1}+B_{j} \\
& c_{2 j}=b_{o 2} k_{o 2}-R_{2} B_{j} \quad j=1,2
\end{aligned}
$$

where $B_{j}$ is the quantity demanded (or supplied) of good 1 in exchange for good 2 and with $\sum_{j} t_{j} B_{j}=0$ across agents determining $R_{2}$, subject to the caveat $R_{2} \geq b_{12}$, the short term realized (storage) rate from $T=1$ to $T=2$. If storage (with $R_{2}=b_{12}$ ) is done then $0 \geq \sum_{j} t_{j} B_{j} \geq-b_{o 1} k_{o 1}$ is the constraint overall.

Individuals maximize their utility functions subject to the above constraints, that is:

Type-1 problem at $T=1$ :

$$
\begin{aligned}
\max _{B_{1}}\left\{\rho_{1} \frac{c_{11}^{1-\gamma}}{1-\gamma}+\left(1-\rho_{1}\right) \frac{c_{21}^{1-\gamma}}{1-\gamma}\right\} \\
\text { s.t: } \quad c_{11}=b_{o 1} k_{o 1}+B_{1} \\
c_{21}=b_{o 2} k_{o 2}-R_{2} B_{1}
\end{aligned}
$$

${ }^{8}$ However, as in Hellwig [1994], the second best allocation may provide for liquidation of the long term asset. 
with solution:

$$
B_{1}=\frac{\left(\frac{1-\rho_{1}}{\rho_{1}} R_{2}\right)^{-1 / \gamma} b_{o 2} k_{o 2}-b_{o 1} k_{o 1}}{1+\left(\frac{1-\rho_{1}}{\rho_{1}} R_{2}\right)^{-1 / \gamma} R_{2}}
$$

Type-2 problem at $T=1$ :

$$
\begin{aligned}
\max _{B_{2}}\left\{\rho_{2} \frac{c_{12}^{1-\gamma}}{1-\gamma}+\left(1-\rho_{2}\right) \frac{c_{22}^{1-\gamma}}{1-\gamma}\right\} \\
\text { s.t: } \quad c_{12}=b_{o 1} k_{o 1}+B_{2} \\
c_{22}=b_{o 2} k_{o 2}-R_{2} B_{2}
\end{aligned}
$$

with solution:

$$
B_{2}=\frac{\left(\frac{1-\rho_{2}}{\rho_{2}} R_{2}\right)^{-1 / \gamma} b_{o 2} k_{o 2}-b_{o 1} k_{o 1}}{1+\left(\frac{1-\rho_{2}}{\rho_{2}} R_{2}\right)^{-1 / \gamma} R_{2}}
$$

Two possibilities may be considered:

1. If $R_{2} \geq b_{12}$

From the equilibrium condition $\sum_{j} t_{j} B_{j}=0$, the following non-linear equation in $R_{2}$ is obtained, that is:

$$
t \frac{\left(\frac{1-\rho_{1}}{\rho_{1}} R_{2}\right)^{-1 / \gamma} b_{o 2} k_{o 2}-b_{o 1} k_{o 1}}{1+\left(\frac{1-\rho_{1}}{\rho_{1}} R_{2}\right)^{-1 / \gamma} R_{2}}+(1-t) \frac{\left(\frac{1-\rho_{2}}{\rho_{2}} R_{2}\right)^{-1 / \gamma} b_{o 2} k_{o 2}-b_{o 1} k_{o 1}}{1+\left(\frac{1-\rho_{2}}{\rho_{2}} R_{2}\right)^{-1 / \gamma} R_{2}}=0
$$

The value of $R_{2}^{*}$ is obtained as a solution to the above equation, and from it the values of $B_{1}^{*}$ and $B_{2}^{*}$ are derived. These values are substituted in the expressions for $c_{11}, c_{21}$ and $c_{12}, c_{22}$, to calculate ex ante expected utility in this economy, or equivalently, the level of risk sharing that can be achieved in a Walrasian market.

2. If $b_{12}>R_{2}$

In this case the equilibrium interest rate is $R_{2}^{*}=b_{12}$, the realized short term return.

The optimal levels of $B_{1}^{*}$ and $B_{2}^{*}$ are:

$$
B_{1}^{*}=\frac{\left(\frac{1-\rho_{1}}{\rho_{1}} b_{12}\right)^{-1 / \gamma} b_{o 2} k_{o 2}-b_{o 1} k_{o 1}}{1+\left(\frac{1-\rho_{1}}{\rho_{1}} b_{12}\right)^{-1 / \gamma} b_{12}} \quad B_{2}^{*}=\frac{\left(\frac{1-\rho_{2}}{\rho_{2}} b_{12}\right)^{-1 / \gamma} b_{o 2} k_{o 2}-b_{o 1} k_{o 1}}{1+\left(\frac{1-\rho_{2}}{\rho_{2}} b_{12}\right)^{-1 / \gamma} b_{12}}
$$


and from them, the optimal consumption levels and the value of the expected utility are obtained. For the parameter values of the example, the solution to equation [28] yields $R_{2}=1.2959$. As in Hellwig's case, ${ }^{9}$ this price coincides with the limit value $b_{2}$ above which there is re-investment in the new short term asset, in the second best allocation. As commented above, for values of the random return below 1.2959 the equilibrium price (of good 1 in exchange for good 2) will be 1.2959 and otherwise, the equilibrium price in the market will be the realized short term return. Figure 3 plots the optimal consumption levels in the equity economy. If we compare these consumption levels with the second best allocation represented in Figure 2, it can be observed that for values of the random return below $b_{2}$ consumption for type 1 agents in both periods is always higher with the demand deposit contract and consumption of type 2 agents is higher in the equity economy. For values of the random return above $b_{2}$ both solutions coincide.

In order to compare the expected utility obtained in the second best allocation or non traded solution with respect to the traded one, some numerical examples have been computed. The input data are those corresponding to Table 1, where the variations in the exogenous parameters and the results of these comparisons are shown from Figure 4 to Figure 7.

A general feature to all the examples is that the non traded solution is always welfare superior for values of the random return below $b_{2}$. As the random return increases the difference in utility becomes zero. This means that at least for low values of $b_{12}$, the demand deposit contract can accomplish greater risk sharing than the equity contract. This is explained by the fact that individuals are being insured against being type 1 to a greater extent than in the traded case (the stream preferred by type 1 agents represents more wealth than the stream preferred by type 2 ).

The intuition for this result can be viewed in terms of individual versus coalition incentive compatibility. (See Jacklin [1987]). "Since demand deposits cannot be traded, they can be used to achieve any allocation that is individually incentive compatible. On the other hand, the allocation achieved in the traded solution is a competitive equilibrium and thus represents an element in the core of the economy in which individuals start trading with identical initial endowments. By definition all elements in the core are not only individually incentive compatible but also coalitionally incentive compatible (that is, there does not exist a coalition of individuals each of whom can be made better off by following a strategy specified by the coalition and then redistributing the coalition's total allocation).

In both the demand deposit and equity economies, the same objective function (i.e., ex ante expected utility) is being maximized but, in the non traded

\footnotetext{
${ }^{9}$ See the analytical example in the next section.
} 


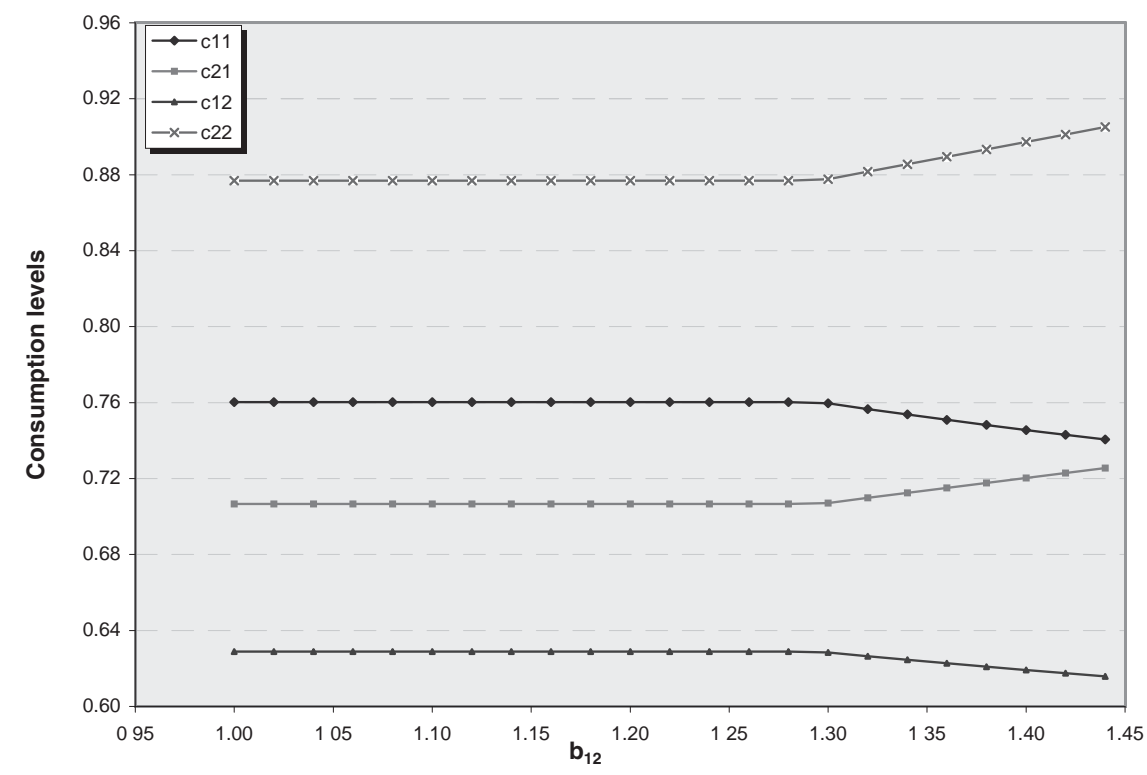

\begin{tabular}{|r|c|c|c|c|c|}
\hline $\mathrm{b}_{12}$ & $\mathrm{R}^{*}{ }_{2}$ & $\mathrm{C}_{11}$ & $\mathrm{C}_{21}$ & $\mathrm{C}_{12}$ & $\mathrm{C}_{22}$ \\
\hline 1.00 & 1.30 & 0.76023 & 0.70663 & 0.62889 & 0.87683 \\
1.02 & 1.30 & 0.76023 & 0.70663 & 0.62889 & 0.87683 \\
1.04 & 1.30 & 0.76023 & 0.70663 & 0.62889 & 0.87683 \\
1.06 & 1.30 & 0.76023 & 0.70663 & 0.62889 & 0.87683 \\
1.08 & 1.30 & 0.76023 & 0.70663 & 0.62889 & 0.87683 \\
1.10 & 1.30 & 0.76023 & 0.70663 & 0.62889 & 0.87683 \\
1.12 & 1.30 & 0.76023 & 0.70663 & 0.62889 & 0.87683 \\
1.14 & 1.30 & 0.76023 & 0.70663 & 0.62889 & 0.87683 \\
1.16 & 1.30 & 0.76023 & 0.70663 & 0.62889 & 0.87683 \\
1.18 & 1.30 & 0.76023 & 0.70663 & 0.62889 & 0.87683 \\
1.20 & 1.30 & 0.76023 & 0.70663 & 0.62889 & 0.87683 \\
1.22 & 1.30 & 0.76023 & 0.70663 & 0.62889 & 0.87683 \\
1.24 & 1.30 & 0.76023 & 0.70663 & 0.62889 & 0.87683 \\
1.26 & 1.30 & 0.76023 & 0.70663 & 0.62889 & 0.87683 \\
1.28 & 1.30 & 0.76023 & 0.70663 & 0.62889 & 0.87683 \\
\hline 1.30 & 1.30 & 0.75961 & 0.70716 & 0.62848 & 0.87763 \\
1.32 & 1.32 & 0.75664 & 0.70979 & 0.62650 & 0.88157 \\
1.34 & 1.34 & 0.75375 & 0.71242 & 0.62458 & 0.88550 \\
1.36 & 1.36 & 0.75095 & 0.71504 & 0.62272 & 0.88943 \\
1.38 & 1.38 & 0.74822 & 0.71767 & 0.62092 & 0.89335 \\
1.40 & 1.40 & 0.74558 & 0.72030 & 0.61917 & 0.89727 \\
1.42 & 1.42 & 0.74301 & 0.72293 & 0.61748 & 0.90118 \\
1.44 & 1.44 & 0.74052 & 0.72555 & 0.61584 & 0.90509 \\
\hline
\end{tabular}

Figure 3: Optimal Consumption Levels in the Walrasian Market 


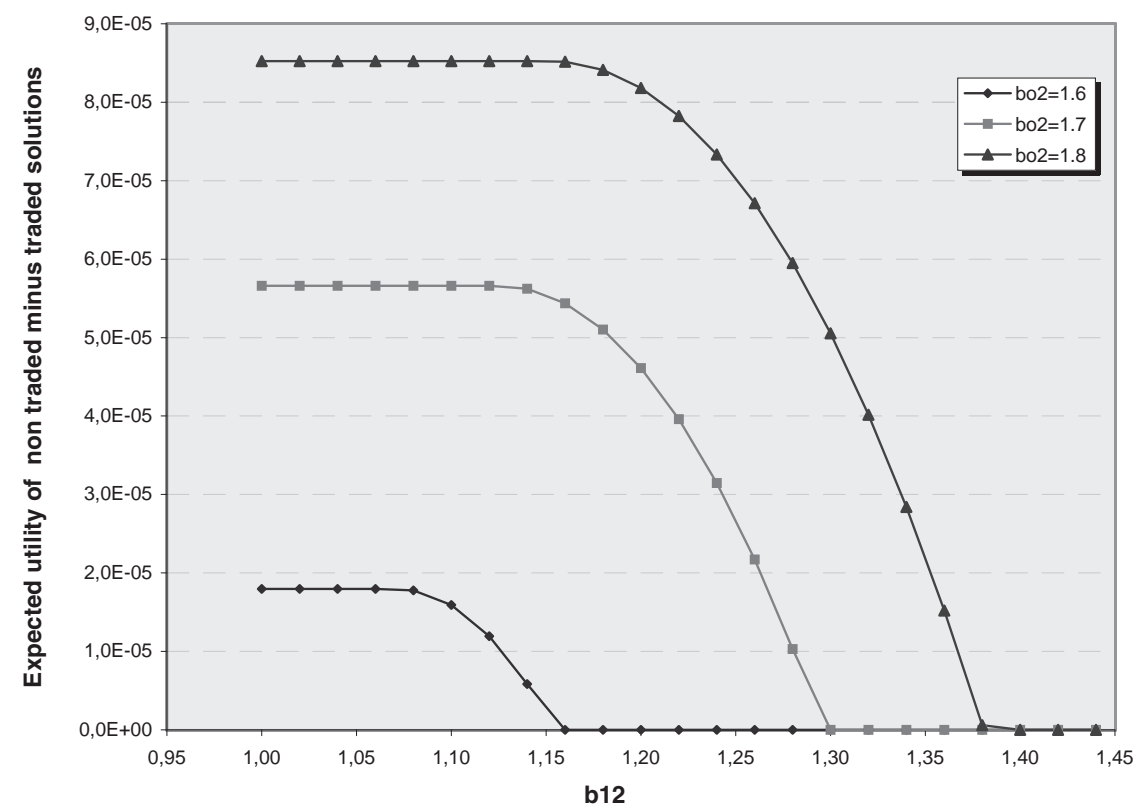

Figure 4: Variation in the Long Term Asset Return

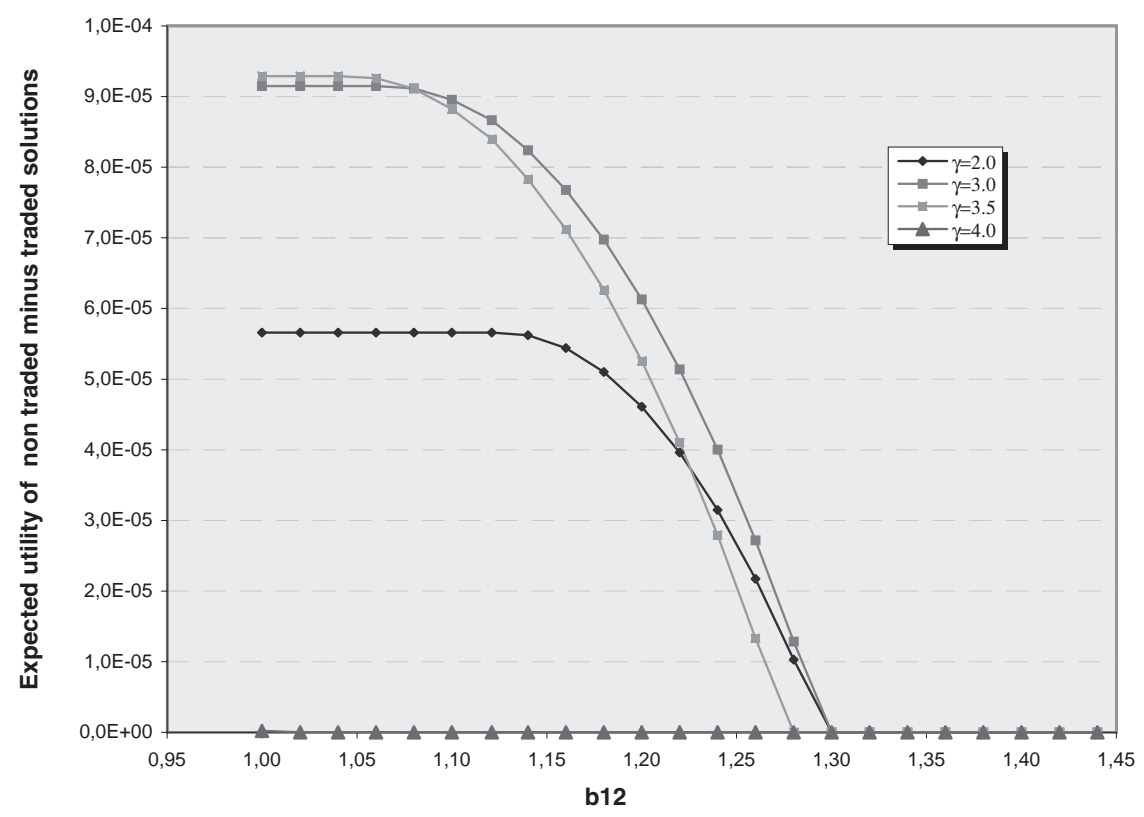

Figure 5: Variation in $\gamma$ 


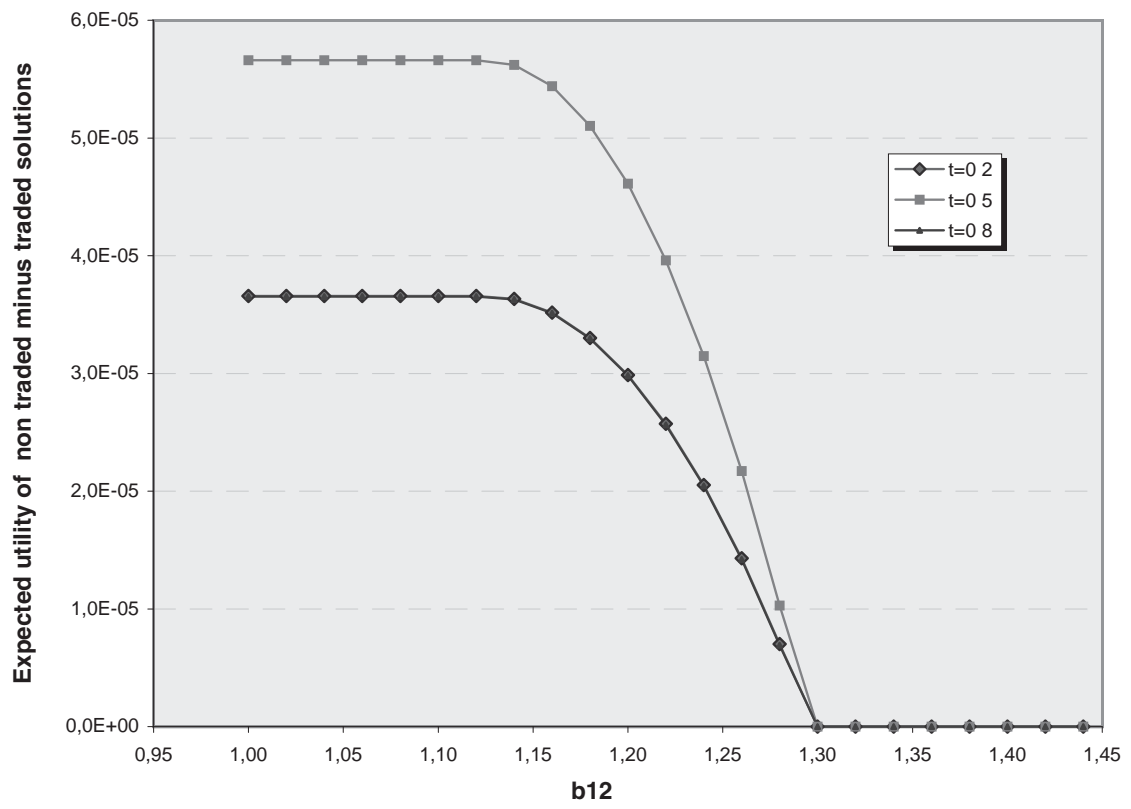

Figure 6: Variation in the Proportion of Consumers of Type 1 Consumers

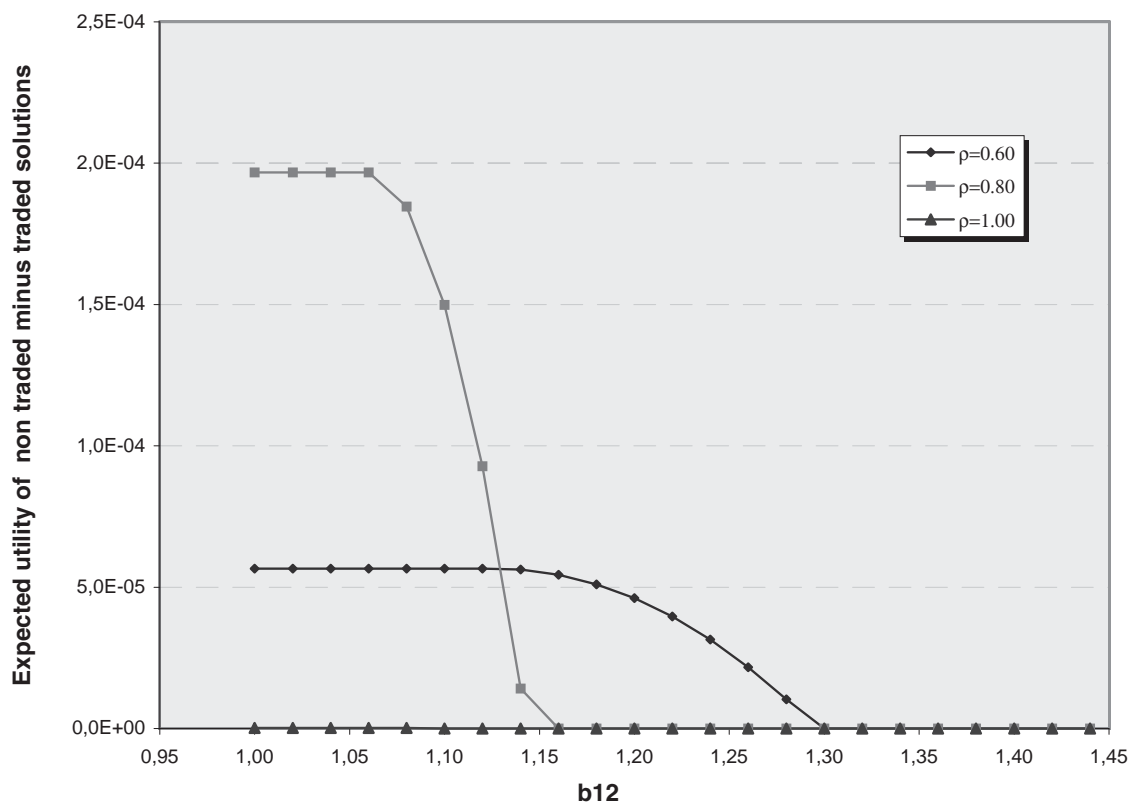

Figure 7: Variation in $\rho$ 
solution, it is maximized over a less constrained set and therefore demand deposits can generally achieve greater risk sharing than equity contracts.

However, as mentioned above, the limit value $b_{2}$ is essential in order to determine the superiority of demand deposit contracts over equity contracts. This critical value depends on the exogenous parameters of the model. In Figure 4, the variation has been carried out with respect to the long term asset return $\left(b_{o 2}\right)$. If the long term asset return increases, this limit value of the interest rate above which it becomes optimal to reinvest some of the return available at date 1 in the new short term asset, also increases. This makes sense intuitively, given the high value of the long term asset return it is not so interesting to reinvest the returns available at date 1 in the new short term asset. Therefore, as $b_{o 2}$ increases, demand deposits are preferred to equity to a greater extent. ${ }^{10}$ Figure 5 shows that if risk aversion $(\gamma)$ increases then the limit value decreases. For very high values of $\gamma$ the limit value would be so low that in this case demand deposits and traded contracts would attain the same level of risk sharing. This may be explained by the reverse-hedging results of Breeden [1984]. He shows that for the CRRA utility functions if individuals are sufficiently risk averse they may choose to reverse hedge, that is, they prefer to consume less now in order to invest in the uncertain future. Figure 6 shows that the variation in the proportion of type 1 consumers does not influence the limit value.

Finally, Figure 7 illustrates that in Hellwig's case $\left(\rho=\rho_{1}=1-\rho_{2}=1\right)$ demand deposit and equity contracts are always equivalent risk sharing instruments.

It may be concluded that, if agents have smooth preferences, represented by an additive utility function, and there is some type of aggregate risk, technology induced interest rate risk, the allocations obtained in the non traded solution are welfare superior with respect to the ones achieved in the traded one, if the interest rate is below a limit value $\left(b_{2}\right)$. Otherwise, both solutions are equivalent. This limit value depends on the level of risk aversion in the population, the long and the short term asset returns.

Finally, one comment should be added regarding the equity versus bank contract comparison. As argued by Jacklin [1987] and Wallace [1988], equity and bank contracts are not compatible in the same economy, since arbitrage by issuing equity against deposits between periods 1 and 2, would eliminate the kind of risk sharing offered by banks. One way to motivate banks, is as suggested in Wallace [1988]: If agents are isolated at date 1 , then no asset markets can operate and bank contracts will survive. However, if this assumption is used to motivate banks in the Jacklin and Bhattacharya [1988] framework or in this paper, then the bank versus equity comparison lacks content. Therefore, the way to interpret the exercise in this paper (as in Jacklin and Bhattacharya [1988]) is

\footnotetext{
${ }^{10}$ Similarly, it could be shown that increasing the short term return $\left(b_{o 1}\right)$ would decrease the limit value, and hence demand deposits would be preferred to equity to a lower extent.
} 
that both equity and banking arrangements are feasible, but there is a financial regulation allowing only one of these arrangements to exist in each case. ${ }^{11}$ This comparison between the discussed arrangements can be used for evaluating this particular kind of government regulation.

\section{AN ANALYTICAL EXAMPLE: HELLWIG'S CASE}

The aim of this section is to provide analytical results for a special case, in which individuals have corner preferences. This means that in the utility function specification given by equation [1] $\rho_{1}=1$ and $\rho_{2}=0$, so that the utility function can be simplified to:

$$
U^{i}\left(c_{i}\right)=\frac{c_{i}^{1-\gamma}}{1-\gamma}
$$

where: $i=$ type $=1,2$. In this case type 1 agents derive only utility for consumption at $T=1$ whereas type 2 agents derive utility for consumption at $T=2$. All the other assumptions of the model are assumed to remain constant.

We will compare the second best outcome to the allocations achieved in the equity economy. It will be shown that in this case, demand deposit and equity contracts are always equivalent risk sharing instruments.

\section{The Second Best Allocation}

The second best problem is a solution to the following one: ${ }^{12}$

$$
\max _{\tilde{c}_{1}, \tilde{c}_{2} k_{o 1}, k_{o 2}, \tilde{\mu}} E\left[t U\left(\tilde{c}_{1}\right)+(1-t) U\left(\tilde{c}_{2}\right)\right]
$$

$$
\begin{array}{ll}
\text { s.t } & k_{o 1}+k_{o 2}=k_{o} \\
& t \tilde{c}_{1} \leq b_{o 1} k_{o 1}+b_{1} \tilde{\mu} k_{o 2} \\
& (1-t) \tilde{c}_{2}=b_{o 2}(1-\tilde{\mu}) k_{o 2}+\tilde{b}_{12}\left[b_{o 1} k_{o 1}+b_{1} \tilde{\mu} k_{o 2}-t \tilde{c}_{1}\right] \\
& \tilde{c}_{1} \tilde{b}_{12} \leq \tilde{c}_{2} \\
& \tilde{\mu} \leq 1 \\
& \tilde{c}_{i} \geq 0 \\
& \tilde{\mu} \geq 0 \\
& k_{o 1} \geq 0 \\
& k_{o 2} \geq 0
\end{array}
$$

\footnotetext{
${ }^{11}$ An interesting addition to this recent literature are the papers by Diamond [1997] and Von Thadden [1998] that allow for the coexistence of banks and markets.

${ }^{12}$ Notice that in this case there is only one incentive constraint, for type 2 agents, given by $\tilde{c}_{1} \tilde{b}_{12} \leq \tilde{c}_{2}$.
} 
The solution to the second best problem is given by the following lemma:

Lemma 1. Let $\left(k_{o 1}^{*}, k_{o 2}^{*}, c_{1}^{*}, c_{2}^{*}, \mu^{*}\right)$ be a solution to the first best problem and define:

$$
\bar{b}_{1}=\frac{\left[\frac{b_{o 2} k_{o 2}}{1-t}\right]^{-\gamma} b_{o 2}}{\left[\frac{b_{o 1} k_{o 1}}{t}\right]^{-\gamma}} \quad b_{2}^{*}=\frac{t b_{o 2} k_{o 2}}{(1-t) b_{o 1} k_{o 1}} \quad b_{2}^{* *}=\left[\frac{b_{o 2}}{b_{1}}\right]^{1 / \gamma}
$$

a) If $b_{1} \leq \bar{b}_{1}$ : then $\mu^{*}=0$

$$
\begin{array}{ll}
\text { If } b_{12} \leq b_{2}^{*}: & \tilde{c}_{1}^{*}=\frac{b_{o 1} k_{o 1}}{t} \quad \tilde{c}_{2}^{*}=\frac{b_{o 2} k_{o 2}}{1-t} \\
\text { If } b_{12} \geq b_{2}^{*}: & \tilde{c}_{1}^{*}=\frac{b_{o 2} k_{o 2}}{\tilde{b}_{12}}+b_{o 1} k_{o 1} \quad \tilde{c}_{2}^{*}=c_{1}^{*} \tilde{b}_{12}
\end{array}
$$

b) If $b_{1}>\bar{b}_{1}$ : then $\mu^{*}=\max \left[0, \frac{b_{o 1} k_{o 1}-t c_{1}^{*}}{b_{1} k_{o 2}}\right]$

$$
\begin{aligned}
& \text { If } b_{12} \leq b_{2}^{* *}: \quad \tilde{c}_{1}^{*}=\frac{\left(b_{o 1} k_{o 1}+k_{o 2} b_{1}\right) b_{o 2}}{t b_{o 2}+(1-t) b_{1}\left[\frac{b_{o 2}}{b_{1}}\right]^{1 / \gamma}} \quad \tilde{c}_{2}^{*}=\left[\frac{b_{o 2}}{b_{1}}\right]^{1 / \gamma} c_{1}^{*} \\
& \text { If } b_{12} \in\left(b_{2}^{* *}, b_{2}^{*}\right): \quad \tilde{c}_{1}^{*}=\frac{b_{o 1} k_{o 1} \frac{b_{o 2}}{b_{1}}+b_{o 2} k_{o 2}}{t\left[\frac{b_{o 2}}{b_{1}}\right]+(1-t) \tilde{b}_{12}} \quad \tilde{c}_{2}^{*}=\tilde{b}_{12} c_{1}^{*} \\
& \text { If } b_{12} \geq b_{12}^{*}: \quad \tilde{c}_{1}^{*}=\frac{b_{o 2} k_{o 2}}{\tilde{b}_{12}}+b_{o 1} k_{o 1} \quad \tilde{c}_{2}^{*}=c_{1}^{*} \tilde{b}_{12}
\end{aligned}
$$

Proof: See Appendix C.

It can be observed that the second best solution may provide for liquidation of the long term asset. In fact, if the liquidation value of the long term technology is below a limit value $\bar{b}_{1}$, then, it is never optimal to liquidate the long term investment, and the consumption levels are those given by lemma 1 (point a). ${ }^{13}$ Otherwise, if $b_{1}>\bar{b}_{1}$, then there may be partial liquidation of the long term asset and the optimal consumption levels are given by lemma 1 (point b). A general feature to both cases is that for low values of the random return consumption is constant, independently of $b_{12}$, and once a limit value is attained $\left(b_{2}^{*}\right.$ or $b_{2}^{* *}$ ) consumption depends on the random return.

\footnotetext{
${ }^{13}$ Similarly, the non-liquidation case could be expressed in terms of $k_{o 1}$, that is, if $k_{o 1} \geq$ $k_{1}=\frac{t b_{o 2}}{b_{o 1}(1-t)\left(\frac{b_{1}}{b_{o 2}}\right)^{-1 / \gamma}+t b_{o 2}}$, then, it is never optimal to liquidate the long term investment.
} 


\section{THE EQUiTy ECONOMY}

Following the definition of Section 3, an equity contract is as a contract that for each unit invested at $T=0$ returns a two period dividend stream $b_{o 1} k_{o 1}$ at $T=1$ and $b_{o 2} k_{o 2}$ at $T=2$. Implicit in this definition is the existence of a market in ex-dividend claims at $T=1$. Let $R_{2}=1+r$ be some equilibrium interest rate at which individuals are willing to trade good 1 in exchange for good 2.

However, with corner preferences, type $1 \mathrm{~s}$ will always exchange their total second period endowment $\left(b_{o 2} k_{o 2}\right)$ against $b_{o 2} k_{o 2} / R_{2}$ units of the date 1 good. Similarly, type 2 agents will exchange their first period endowment $\left(b_{o 1} k_{o 1}\right)$ against $b_{o 1} k_{o 1} R_{2}$ units of the date 2 good.

Consumption of type 1 agents at $T=1$ will be:

$$
c_{1}=b_{o 1} k_{o 1}+\frac{b_{o 2} k_{o 2}}{R_{2}}
$$

Similarly, consumption of type 2 agents at $T=2$ will be:

$$
c_{2}=b_{o 1} k_{o 1} R_{2}+b_{o 2} k_{o 2}
$$

Two possibilities may be considered:

1. If $R_{2} \geq \tilde{b}_{12}$

From the market clearing condition $t b_{o 2} k_{o 2} / R_{2}=(1-t) b_{o 1} k_{o 1}$ it is obtained that $R_{2}^{*}=\frac{t b_{02} k_{o 2}}{(1-t) b_{01} k_{o 1}}$. This price coincides with the limit value $b_{2}^{*}$ of the second best allocation. Substituting this price in equations [39] and [40] we obtain:

$$
c_{1}^{*}=\frac{b_{o 1} k_{o 1}}{t} \quad c_{2}^{*}=\frac{b_{o 2} k_{o 2}}{1-t}
$$

2. If $\tilde{b}_{12}>R_{2}$ :

In this case the equilibrium interest rate is the realized short term return, i.e., $R_{2}^{*}=\tilde{b}_{12}$ and the optimal consumption levels would be:

$$
c_{1}^{*}=b_{o 1} k_{o 1}+\frac{b_{o 2} k_{o 2}}{\tilde{b}_{12}} \quad c_{2}^{*}=b_{o 1} k_{o 1} \tilde{b}_{12}+b_{o 2} k_{o 2}
$$

It can observed that the optimal consumption levels coincide with the ones given by lemma 1 (point a): Demand deposit contracts and equity contracts are equivalent risk sharing instruments.

Finally, it remains to be shown that this is also true when there is partial liquidation of the long term technology. In this case the first and second period endowments of individuals would become $b_{o 1} k_{o 1}+b_{1} \mu k_{o 2}$ and $b_{o 2} k_{o 2}(1-\mu)$ respectively, in order to take into account the possibility of premature liquidation of the long term asset at $T=1$. 
Following the same reasoning as in the previous case, type 1 individuals will completely exchange their second period endowment with type 2 , in exchange for the first period one.

Consumption of type 1 agents at $T=1$ will be:

$$
c_{1}=b_{o 1} k_{o 1}+b_{1} \mu k_{o 2}+\frac{b_{o 2} k_{o 2}(1-\mu)}{R_{2}}
$$

Consumption of type 2 agents at $T=2$ will be:

$$
c_{2}=\left(b_{o 1} k_{o 1}+b_{1} \mu k_{o 2}\right) R_{2}+b_{o 2} k_{o 2}(1-\mu)
$$

As before two possibilities may be considered:

1. If $R_{2} \geq \tilde{b}_{12}$

From the market clearing condition $t b_{o 2} k_{o 2}(1-\mu) / R_{2}=(1-t)\left(b_{o 1} k_{o 1}+\right.$ $b_{1} \mu k_{o 2}$ ), and substituting the value of $\mu$ given in lemma 1 , it is obtained that $R_{2}^{*}=\left[\frac{b_{o 2}}{b_{1}}\right]^{1 / \gamma}$. This price coincides with the limit value $b_{2}^{* *}$ of the second best allocation.

2. If $\tilde{b}_{12}>R_{2}$

The equilibrium interest rate will be the realized short term return.

Substituting the equilibrium prices in equations [43] and [44] it can also be shown that we obtain the optimal consumption levels given by lemma 1 (point b). ${ }^{14}$

\section{CONCLUDING REMARKS}

The aim of this paper is to compare the welfare properties of banking arrangements with those where the intertemporal allocation is achieved using equity contracts. The paper considers a model in which there is a random short term technology or interest rate risk (as in Hellwig [1994]), and individuals derive utility for consumption in both periods of their lives. The optimal allocation of technology-induced interest rate risk can be implemented by a financial intermediary, using a demand deposit contract. The paper shows, using numerical examples, that the level of risk sharing achieved with a demand deposit contract is in general higher than with an equity contract. This result confirms

\footnotetext{
${ }^{14}$ It should be mentioned that this liquidation case has not been considered in the more general (smooth preference case) of Section III. However, this would have added an additional complication into the analysis without changing the essence of the result: the superiority of demand deposits over equity contracts depends on the limit value of the interest rate.
} 
the important role financial institutions perform, as providers of liquidity, even though, in providing this service they may be vulnerable to bank runs. ${ }^{15}$ However, the superiority of demand deposits over equity contracts depends on a critical value of the interest rate: for values of the interest rate below this critical one, demand deposits accomplish greater risk sharing than equity contracts, otherwise both solutions coincide. This critical value depends on the level of risk aversion in the population, the short and the long term asset returns. The contribution of this paper is to show that with smooth preferences and interest rate risk, this latter variable plays a crucial role in order to determine the superiority of demand deposits over equity contracts.

\section{REFERENCES}

Bhattacharya, S. and J. Padilla. 1996. "Dynamic banking, a reconsideration." Review of Financial Studies 9:1003-1032.

Boot, A., S. Bhattacharya, and A. Thakor. 1998. "The economics of bank regulation." Journal of Money, Credit and Banking 30:745-770.

Breeden. D. 1984. "Futures markets and commodity options: Hedging and optimality in incomplete markets." Journal of Economic Theory 32:275-300.

Bryant, J. 1980. "A model of reserves, bank runs and deposit insurance." Journal of Banking and Finance 4:335-344.

Diamond, D. 1997. "Liquidity, banks and markets." Journal of Political Economy 5:928-056.

Diamond, D. and P. Dybvig. 1983. "Bank runs, deposit insurance and liquidity." Journal of Political Economy 91(3):401-419.

Dutta, J. and S. Kapur. 1994. "Liquidity preference and financial intermediation." Discussion Papers in Economics. Birbeck College, P. 17.

Fulghieri, P., S. Bhattacharya, and R. Roveli. 1998. Financial intermediation versus sock markets in a dynamic intertemporal model. Journal of Institutional and Theoretical Economics 154:291-318.

Fulghieri, P. and R. Rovelli. 1999. "Capital markets, financial intermediation and the supply of liquidity in a dynamic economy." Working Papers in Economics. Graduate School of Business. Columbia University, 93-04.

Hellwig, M. 1994. "Liquidity provision, banking and the allocation of interest rate risk." European Economic Review 38:1363-1389.

Jacklin, C. 1987. "Demand Deposits, Trading Restrictions and Risk Sharing." Pp. 26-47 in Contractual Arrangements for Interptemporal Trade, eds. E. C. Prescott and N. Wallace. Minnesota: University of Minnesota Press.

${ }^{15}$ This result confirms one of the major conclusions summarized in Bhattacharya, Bhoot and Thakor [1998]: "The use of sequentially service-constrained demandable debt, without interest rate restrictions, in bank financing may provide superior intertemporal risk sharing. Given this, productively bank runs and panics may arise as Nash equilibrium phenomena" (page 765). 
Jacklin, C. 1993. "Market rate versus fixed rate demand deposits." Journal of Monetary Economics 32:237-258.

Jacklin, C. and S. Bhattcharya. 1988. "Distinguishing panics and information-based bank runs: Welfare and policy implications." Journal of Political Economy 96:568592.

Von Thadden, E. 1998. "Intermediated versus direct investment: Optimal liquidity provision and dynamic incentive compatibility." Journal of Financial Intermediation 7:177-197.

Wallace, N. 1998. "Another attempt to explain an illiqid banking system: the Diamond Dybvig with sequential service taken seriously." Quarterly Review of the Federal Reserve Bank of Minneapolis 3-16.

\section{APPENDICES}

\section{Appendix A: First Best Allocation}

\section{First-step Solution}

In the first step, $k_{o 1}$ and $k_{o 2}$ are considered as exogenous parameters and so the problem to be solved is the following one:

$$
\max _{c_{i j}, \mu}\left\{t\left[\rho_{1} \frac{c_{11}^{1-\gamma}}{1-\gamma}+\left(1-\rho_{1}\right) \frac{c_{21}^{1-\gamma}}{1-\gamma}\right]+(1-t)\left[\rho_{2} \frac{c_{12}^{1-\gamma}}{1-\gamma}+\left(1-\rho_{2}\right) \frac{c_{22}^{1-\gamma}}{1-\gamma}\right]\right\}
$$

s.t.

$$
\begin{aligned}
t c_{11}+(1-t) c_{12} & \leq b_{o 1} k_{o 1}+\mu k_{o 2} b_{1} \\
t c_{21}+(1-t) c_{22} & =(1-\mu) b_{o 2} k_{o 2}+\left[\mu k_{o 2} b_{1}+b_{o 1} k_{o 1}-t c_{11}-(1-t) c_{12}\right] b_{12} \\
c_{i j} & \geq 0 \\
\mu & \geq 0 \\
\mu & \leq 1
\end{aligned}
$$

The Lagrangian is formed by using the lagrangian multipliers $\lambda_{1}$ and $\lambda_{2}$ of the two first resource constraints.

The Kuhn-Tucker conditions are:

$$
\begin{aligned}
t \rho_{1} c_{11}^{-\gamma}-\lambda_{1} t+t b_{12} \lambda_{2} & =0 & & \text { if } c_{11}>0 \\
t\left(1-\rho_{1}\right) c_{21}^{-\gamma}+t \lambda_{2} & =0 & & \text { if } c_{21}>0 \\
(1-t) \rho_{2} c_{12}^{-\gamma}-\lambda_{1}(1-t)+(1-t) b_{12} \lambda_{2} & =0 & & \text { if } c_{12}>0 \\
(1-t)\left(1-\rho_{2}\right) c_{22}^{-\gamma}+(1-t) \lambda_{2} & =0 & & \text { if } c_{22}>0 \\
k_{o 2} b_{1} \lambda_{1}-k_{o 2}\left(b_{1} b_{12}-b_{o 2}\right) \lambda_{2}-\lambda_{3} & =0 & & \text { if } \mu>0 \\
b_{o 1} k_{o 1}+\mu k_{o 2} b_{1}-t c_{11}-(1-t) c_{12} & =0 & & \text { if } \lambda_{1}>0 \\
t c_{21}+(1-t) c_{22}-(1-\mu) b_{o 2} k_{o 2}-\left[\mu k_{o 2} b_{1}+b_{o 1} k_{o 1}\right. & & & \\
\left.-t c_{11}-(1-t) c_{12}\right] b_{12} & =0 & & \forall \lambda_{2} \\
1-\mu & =0 & & \text { if } \lambda_{3}>0
\end{aligned}
$$


The following cases may be considered:

CASE A: $\left(\lambda_{1}>0, \mu^{*}=0\right)$

The equations to be solved are:

$$
\begin{array}{rlll}
\rho_{1} c_{11}^{-\gamma}-\lambda_{1}+b_{12} \lambda_{2}=0 & \text { [a }] & \left(1-\rho_{1}\right) c_{21}^{-\gamma}+\lambda_{2}=0 & {[\mathrm{~b}]} \\
\rho_{2} c_{12}^{-\gamma}-\lambda_{1}+b_{12} \lambda_{2}=0 & {[\mathrm{a}]} & \left(1-\rho_{2}\right) c_{22}^{-\gamma}+\lambda_{2}=0 & {[\mathrm{~b}]} \\
t c_{11}+(1-t) c_{12}-b_{o 1} k_{o 1}=0 & {[\mathrm{a}]} & t c_{21}+(1-t) c_{22}-b_{o 2} k_{o 2}=0 & {[\mathrm{~b}]}
\end{array}
$$

The optimal solution to this problem yields:

$$
\begin{array}{rlrl}
c_{11}^{*} & =\frac{b_{o 1} k_{o 1}}{t+(1-t)\left[\frac{\rho_{1}}{\rho_{2}}\right]^{-1 / \gamma}} & c_{21}^{*} & =\frac{b_{o 2} k_{o 2}}{t+(1-t)\left[\frac{\rho_{2}}{\rho_{1}}\right]^{-1 / \gamma}} \\
c_{12}^{*} & =\left[\frac{\rho_{1}}{\rho_{2}}\right]^{-1 / \gamma} c_{11}^{*} & c_{22}^{*}=\left[\frac{\rho_{2}}{\rho_{1}}\right]^{-1 / \gamma} c_{21}^{*} \quad \mu^{*}=0
\end{array}
$$

In Case $\mathrm{A}$ it is assumed $\lambda_{1}>0$, from equation [49] [a] and [b]:

$$
\lambda_{1}=\rho_{1} c_{11}^{-\gamma}-b_{12}\left(1-\rho_{1}\right) c_{21}^{-\gamma}>0
$$

Substituting $c_{11}^{*}$ and $c_{21}^{*}$ in the expression for $\lambda_{1}$, the following condition on $b_{12}$ for this case to hold is obtained:

$$
b_{12}<b_{\lim }=\left\{\frac{b_{o 1} k_{o 1}\left[t+(1-t)\left(\frac{\rho_{2}}{\rho_{1}}\right)^{-1 / \gamma}\right]}{b_{o 2} k_{o 2}\left[t+(1-t)\left(\frac{\rho_{1}}{\rho_{2}}\right)^{-1 / \gamma}\right]}\right\}^{-\gamma} \frac{\rho_{1}}{1-\rho_{1}}
$$

Similarly it is assumed $\mu^{*}=0$, that means $\frac{\partial L}{\partial \mu} \leq 0$

$$
\frac{\partial L}{\partial \mu} \leq k_{o 2} b_{1} \lambda_{1}-k_{o 2}\left(b_{1} b_{12}-b_{o 2}\right) \lambda_{2} \leq 0
$$

Substituting $\lambda_{1}=\rho_{1} c_{11}^{-\gamma}-b_{12}\left(1-\rho_{1}\right) c_{21}^{-\gamma}$ and $\lambda_{2}=-\left(1-\rho_{1}\right) c_{21}^{-\gamma}$ in the above expression, the condition on $k_{o 1}$, for this case to hold is obtained:

$$
1 \geq k_{o 1} \geq \frac{\left[\frac{b_{o 2}\left(1-\rho_{1}\right)}{b_{1} \rho_{1}}\right]^{-1 / \gamma} b_{o 2}\left[t+(1-t)\left(\frac{\rho_{1}}{\rho_{2}}\right)^{-1 / \gamma}\right]}{\left[\frac{b_{o 2}\left(1-\rho_{1}\right)}{b_{1} \rho_{1}}\right]^{-1 / \gamma} b_{o 2}\left[t+(1-t)\left(\frac{\rho_{1}}{\rho_{2}}\right)^{-1 / \gamma}\right]+b_{o 1}\left[t+(1-t)\left(\frac{\rho_{2}}{\rho_{1}}\right)^{-1 / \gamma}\right]}=\bar{k}
$$

If the optimal level of the initial investment is above this limit value $(\bar{k})$ there is no liquidation in the optimal solution. 
CASE B: $\left(\lambda_{1}=0, \mu^{*}=0\right)$

The F.O.C. in this case are:

$$
\begin{array}{rrr}
\rho_{1} c_{11}^{-\gamma}+b_{12} \lambda_{2}=0 & {[\mathrm{a}]} & \left(1-\rho_{1}\right) c_{21}^{-\gamma}+\lambda_{2}=0 \\
\rho_{2} c_{12}^{-\gamma}+b_{12} \lambda_{2}=0 & {[\mathrm{a}]} & \left(1-\rho_{2}\right) c_{22}^{-\gamma}+\lambda_{2}=0 \\
t c_{21}+(1-t) c_{22}-b_{o 2} k_{o 2}-\left[b_{o 1} k_{o 1}-t c_{11}-(1-t) c_{12}\right] b_{12}=0
\end{array}
$$

and the optimal solution is:

$$
\begin{array}{cl}
\tilde{c}_{12}^{*}=\left[\frac{\rho_{1}}{\rho_{2}}\right]^{-1 / \gamma} \tilde{c}_{11}^{*} & \tilde{c}_{11}^{*}=\left[\frac{\rho_{2}}{\rho_{1}} \tilde{b}_{12}\right]^{-1 / \gamma} \tilde{c}_{21}^{*} \\
\tilde{c}_{21}^{*}=\frac{b_{o 1} b_{12}+b_{o 2} k_{o 2}}{t\left[1+\left(\frac{\rho_{2}}{\rho_{1}}\right)^{-1 / \gamma}+\tilde{b}_{12}^{\gamma-1}\right]+(1-t)\left[\left(\frac{\rho_{2}}{\rho_{1}}\right)^{-1 / \gamma}+b_{12}^{\frac{\gamma-1}{\gamma}}\right]} & \tilde{c}_{22}^{*}=\left[\frac{\rho_{2}}{\rho_{1}}\right]^{-1 / \gamma} \tilde{c}_{21}^{*} \quad \tilde{\mu}^{*}=0
\end{array}
$$

In Case B it is assumed $\lambda_{1}=0$, or equivalently:

$$
t c_{11}^{*}+(1-t) c_{12}^{*} \leq b_{o 1} k_{o 1}
$$

Substituting the optimal consumption levels, the following expression for the random return is obtained:

$$
b_{12} \geq b_{\lim }=\left\{\frac{b_{o 1} k_{o 1}\left[t+(1-t)\left(\frac{\rho_{2}}{\rho_{1}}\right)^{-1 / \gamma}\right]}{b_{o 2} k_{o 2}\left[t+(1-t)\left(\frac{\rho_{1}}{\rho_{2}}\right)^{-1 / \gamma}\right]}\right\}^{-\gamma} \frac{\rho_{1}}{1-\rho_{1}}
$$

CASE C: $\left(\lambda_{1}>0, \mu^{*}>0\right)$

The equations to be solved are the ones given by equation [48] and the optimal solution is:

$$
\begin{aligned}
c_{21}^{*} & =\frac{b_{o 2}\left(b_{o 1} k_{o 1}+b_{1} k_{o 2}\right)}{\left\{t+(1-t)\left[\frac{\rho_{1}}{\rho_{2}}\right]^{-1 / \gamma}\right\}\left[\frac{\rho_{1}}{b_{1}}\right]^{-1 / \gamma} b_{o 2}^{\frac{\gamma-1}{\gamma}}+b_{1}\left\{t+(1-t)\left[\frac{\rho_{2}}{\rho_{1}}\right]^{-1 / \gamma}\right\}} \\
c_{11}^{*} & =\left[\frac{b_{o 2}\left(1-\rho_{1}\right)}{b_{1} \rho_{1}}\right]^{-1 / \gamma} c_{21}^{*} \quad c_{22}^{*}=\left[\frac{\rho_{2}}{\rho_{1}}\right]^{-1 / \gamma} c_{21}^{*} \quad c_{12}^{*}=\left[\frac{\rho_{1}}{\rho_{2}}\right] c_{11}^{*} \\
0 & <\mu^{*}=\frac{t c_{11}^{*}+(1-t) c_{12}^{*}-b_{o 1} k_{o 1}}{b_{1} k_{o 2}}<1
\end{aligned}
$$

In this case, it is assumed a value for $\mu^{*}>0$, that is, substituting $c_{11}^{*}$ and $c_{12}^{*}$ in the expression for $\mu^{*}$, the condition on $k_{o 1}$ for this case to be satisfied is obtained:

$$
k_{o 1}<\frac{\left[\frac{b_{o 2}\left(1-\rho_{1}\right)}{b_{1} \rho_{1}}\right]^{-1 / \gamma} b_{o 2}\left[t+(1-t)\left(\frac{\rho_{1}}{\rho_{2}}\right)^{-1 / \gamma}\right]}{\left[\frac{b_{o 2}\left(1-\rho_{1}\right)}{b_{1} \rho_{1}}\right]^{-1 / \gamma} b_{o 2}\left[t+(1-t)\left(\frac{\rho_{1}}{\rho_{2}}\right)^{-1 / \gamma}\right]+b_{o 1}\left[t+(1-t)\left(\frac{\rho_{2}}{\rho_{1}}\right)^{-1 / \gamma}\right]}=\bar{k}
$$




\section{Second-step Solution}

The second step is the solution to the expression:

$$
\begin{gathered}
\max _{k_{o 1}, k_{o 2}}\left[\begin{array}{cc}
\int_{b_{\min }}^{b_{\text {lim }}} U^{*(A)} f\left(b_{12}\right) d b_{12}+\int_{b_{\lim }}^{b_{\max }} U^{*(B)} f\left(b_{12}\right) d b_{12} & \text { if } k_{o 1} \geq \bar{k} \\
\int_{b_{\min }}^{b_{\max }} U^{*(C)} f\left(b_{12}\right) d b_{12} & \text { if } k_{o 1}<\bar{k}
\end{array}\right] \\
\text { s.t } \quad k_{o 1}+k_{o 2}=k_{o}
\end{gathered}
$$

Then, if $0 \leq k_{o 1}<\bar{k}$ :

$$
\max _{k_{o 1}} \int_{b_{\min }}^{b_{\max }} U^{*(C)} f\left(b_{12}\right) d b_{12} \rightarrow \int_{b_{\min }}^{b_{\max }} \frac{\partial U^{*(C)}}{\partial k_{o 1}} f\left(b_{12}\right) d b_{12}=0
$$

That is, if $\frac{\partial U^{*}(C)}{\partial k_{o 1}}>0$ in the interval $\left[b_{\min }, b_{\max }\right]$, the maximum is reached in $\bar{k}$. The proof is given by:

$$
\frac{\partial U^{*}(C)}{\partial k_{o 1}}=t\left[c_{11}^{*-\gamma} \frac{\partial c_{11}^{*}}{\partial k_{o 1}}+\rho_{1} c_{21}^{*-\gamma} \frac{\partial c_{21}^{*}}{\partial k_{o 1}}\right]+(1-t)\left[c_{12}^{*-\gamma} \frac{\partial c_{12}^{*}}{\partial k_{o 1}}+\rho_{2} c_{22}^{*}-\gamma \frac{\partial c_{22}^{*}}{\partial k_{o 1}}\right]
$$

where:

$$
\begin{aligned}
\frac{\partial c_{21}^{*}}{\partial k_{o 1}} & =\frac{b_{o 2}\left(b_{o 1}-b_{1}\right)}{\left\{t+(1-t)\left[\frac{\rho_{1}}{\rho_{2}}\right]^{-1 / \gamma}\right\}\left[\frac{\rho_{1}}{b_{1}}\right]^{-1 / \gamma} b_{o 2}^{\frac{\gamma-1}{\gamma}}+b_{1}\left\{t+(1-t)\left[\frac{\rho_{2}}{\rho_{1}}\right]^{-1 / \gamma}\right\}} \\
\frac{\partial c_{11}^{*}}{\partial k_{o 1}} & =\left[\frac{b_{o 2}\left(1-\rho_{1}\right)}{b_{1} \rho_{1}}\right]^{-1 / \gamma} \frac{\partial c_{21}^{*}}{\partial k_{o 1}} \quad \frac{\partial c_{22}^{*}}{\partial k_{o 1}}=\left[\frac{\rho_{2}}{\rho_{1}}\right]^{-1 / \gamma} \frac{\partial c_{21}^{*}}{\partial k_{o 1}} \quad \frac{\partial c_{12}^{*}}{\partial k_{o 1}}=\left[\frac{\rho_{1}}{\rho_{2}}\right]^{-1 / \gamma} \frac{\partial c_{11}^{*}}{\partial k_{o 1}}
\end{aligned}
$$

By assumption $b_{1}<b_{o 1}$ and therefore, $\frac{\partial U^{*}(C)}{\partial k_{o 1}}>0$ which implies $k_{o 1}^{*} \geq \bar{k}$, this means that, the optimal solution falls always in $C$ ases $A$ and $B$, with no liquidation of the long-term asset.

\section{Appendix B: Second Best Allocation}

The second best allocation is a solution to the following problem:

$$
\max _{\tilde{c}_{i j}, k_{o 1}, k_{o 2}, \tilde{\mu}} E\left[t U\left(\tilde{c}_{11}, \tilde{c}_{21}, \rho_{1}\right)+(1-t) U\left(\tilde{c}_{12}, \tilde{c}_{22}, \rho_{2}\right)\right]
$$




$$
\begin{array}{ll}
\text { s.t } & k_{o 1}+k_{o 2}=k_{o}=1 \\
& t \tilde{c}_{11}+(1-t) \tilde{c}_{12} \leq b_{o 1} k_{o 1}+b_{1} \tilde{\mu} k_{o 2} \\
& t \tilde{c}_{21}+(1-t) \tilde{c}_{22}=b_{o 2}(1-\tilde{\mu}) k_{o 2}+\tilde{b}_{12}\left[b_{o 1} k_{o 1}+b_{1} \tilde{\mu} k_{o 2}-t \tilde{c}_{11}(1-t) \tilde{c}_{12}\right] \\
& \tilde{\mu} \leq 1 \\
& \tilde{c}_{i j} \geq 0 \\
& \tilde{\mu} \geq 0 \\
& k_{o 1} \geq 0 \\
& k_{o 2} \geq 0
\end{array}
$$

I.C. Constraints

The FOCS are the following ones:

$$
\begin{gathered}
t \rho_{1} c_{11}^{-\gamma}-\lambda_{1} t+t b_{12} \lambda_{2}+c_{11}^{-\gamma} \lambda_{4} \rho_{1} \\
-\left\{\left[\left(\frac{1-\rho_{2}}{\rho_{2}}\right)^{-1 / \gamma} \frac{b_{12}^{-1 / \gamma} c_{21}+b_{12}^{g} c_{11}}{b}\right]^{-\gamma}\left(\frac{1-\rho_{2}}{\rho_{2}}\right)^{-1 / \gamma} \rho_{2} \frac{b_{12}^{g}}{b}\right. \\
\left.+\left[\frac{c_{21}+b_{12} c_{11}}{b}\right]^{-\gamma}\left(1-\rho_{2}\right) \frac{b_{12}}{b}\right\} \lambda_{5}=0 \quad \text { if } c_{11}>0 \\
t\left(1-\rho_{1}\right) c_{21}^{-\gamma}+t \lambda_{2}+\left(1-\rho_{1}\right) c_{21}^{-\gamma} \lambda_{4} \\
-\left\{\left[\left(\frac{1-\rho_{2}}{\rho_{2}}\right)^{-1 / \gamma} \frac{b_{12}^{-1 / \gamma} c_{21}+b_{12}^{g} c_{11}}{b}\right]^{-\gamma}\left(\frac{1-\rho_{2}}{\rho_{2}}\right)^{-1 / \gamma} \rho_{2} \frac{b_{12}^{-1 / \gamma}}{b}\right. \\
\left.+\left[\frac{c_{21}+b_{12} c_{11}}{b}\right]^{-\gamma} \frac{\left(1-\rho_{2}\right)}{b}\right\} \lambda_{5}=0 \quad \text { if } c_{21}>0 \\
(1-t) \rho_{2} c_{12}^{-\gamma}-\lambda_{1}(1-t)+(1-t) b_{12} \lambda_{2}+c_{12}^{-\gamma} \rho_{2} \lambda_{5} \\
-\left\{\left[\left(\frac{1-\rho_{1}}{\rho_{1}}\right)^{-1 / \gamma} \frac{b_{12}^{-1 / \gamma} c_{22}+b_{12}^{g} c_{12}}{a}\right]^{-\gamma}\left(\frac{1-\rho_{1}}{\rho_{1}}\right)^{-1 / \gamma} \frac{b_{12}^{g}}{a} \rho_{1}\right. \\
\left.+\left[\frac{c_{22}+b_{12} c_{12}}{a}\right]^{-\gamma}\left(1-\rho_{1}\right) \frac{b_{12}}{a}\right\}^{-\gamma}=0 \quad \text { if } c_{12}>0 \\
(1-t)\left(1-\rho_{2}\right) c_{22}^{-\gamma}+(1-t) \lambda_{2}+\left(1-\rho_{2}\right) c_{22}^{-\gamma} \lambda_{5} \quad \text { if } \lambda_{3}>0 \\
-\left\{\left[\left(\frac{1-\rho_{1}}{\rho_{1}}\right)^{-1 / \gamma} \frac{b_{12}^{-1 / \gamma} c_{22}+b_{12}^{g} c_{12}}{a}\right]^{-\gamma}\left(\frac{1-\rho_{1}}{\rho_{1}}\right)^{-1 / \gamma} \frac{b_{12}^{-1 / \gamma}}{a} \rho_{1}\right. \\
\left.+\left[\frac{c_{22}+b_{12} c_{12}}{a}\right]^{-\gamma} \frac{\left(1-\rho_{1}\right)}{a}\right\} \lambda_{4}=0 \quad \text { if } c_{22}>0 \\
k_{o 2} b_{1} \lambda_{1}-k_{o 2}\left(b_{1} b_{12}-b_{o 2}\right) \lambda_{2}-\lambda_{3}=0 \quad \text { if } \mu>0 \\
t c_{11}+(1-t) c_{12}-b_{o 1} k_{o 1}-\mu k_{o 2} b_{1}=0 \quad \text { if } \lambda_{1}>0
\end{gathered}
$$




$$
\begin{aligned}
& \frac{\left\{\rho_{1} c_{11}^{1-\gamma}+\left(1-\rho_{1}\right) c_{21}^{1-\gamma}-\rho_{1}\left[\left(\frac{1-\rho_{1}}{\rho_{1}}\right)^{-1 / \gamma} \frac{b_{12}^{-1 / \gamma} c_{22}+b_{12}^{g} c_{12}}{a}\right]^{1-\gamma}-\left(1-\rho_{1}\right)\left[\frac{c_{22}+b_{12} c_{12}}{a}\right]^{1-\gamma}\right\}}{1-\gamma}=0 \\
& \text { if } \lambda_{4}>0 \\
& \frac{\left\{\rho_{2} c_{12}^{1-\gamma}+\left(1-\rho_{2}\right) c_{22}^{1-\gamma}-\rho_{2}\left[\left(\frac{1-\rho_{2}}{\rho_{2}}\right)^{-1 / \gamma} \frac{b_{12}^{-1 / \gamma} c_{21}+b_{12}^{g} c_{11}}{b}\right]^{1-\gamma}-\left(1-\rho_{2}\right)\left[\frac{c_{21}+b_{12} c_{11}}{b}\right]^{1-\gamma}\right\}}{1-\gamma}=0 \\
& \quad \text { if } \lambda_{5}>0
\end{aligned}
$$

and where:

$$
g=\frac{\gamma-1}{\gamma} a=1+b_{12}^{g}\left(\frac{1-\rho_{1}}{\rho_{1}}\right)^{-1 / \gamma} b=1+b_{12}^{g}\left(\frac{1-\rho_{2}}{\rho_{2}}\right)^{-1 / \gamma}
$$

\section{ApPENDix C: Hellwig’s CASE}

The second best allocation is obtained as a solution to the following problem:

$$
\begin{array}{ll} 
& \max _{\tilde{c}_{1}, \tilde{c}_{2} k_{o 1}, k_{o 2}, \tilde{\mu}} E\left[t U\left(\tilde{c}_{1}\right)+(1-t) U\left(\tilde{c}_{2}\right)\right] \\
\text { s.t } \quad k_{o 1}+k_{o 2}=k_{o} & \\
& t \tilde{c}_{1} \leq b_{o 1} k_{o 1}+b_{1} \tilde{\mu} k_{o 2} \\
& (1-t) \tilde{c}_{2}=b_{o 2}(1-\tilde{\mu}) k_{o 2}+\tilde{b}_{12}\left[b_{o 1} k_{o 1}+b_{1} \tilde{\mu} k_{o 2}-t \tilde{c}_{1}\right] \\
& \tilde{c}_{1} \tilde{b}_{12} \leq \tilde{c}_{2} \\
& \tilde{\mu} \leq 1 \\
& \tilde{c}_{i} \geq 0 \\
& \tilde{\mu} \geq 0 \\
& k_{o 1} \geq 0 \\
& k_{o 2} \geq 0
\end{array}
$$

\section{First-step Solution}

In a first step, $k_{o 1}$ and $k_{o 2}$ are considered as exogenous parameters to the model and the optimal consumption levels and liquidation policy are determined. The problem to be solved becomes the following one:

$$
\max _{\tilde{c}_{1}, \tilde{c}_{2}, \tilde{\mu}} E\left[t U\left(\tilde{c}_{1}\right)+(1-t) U\left(\tilde{c}_{2}\right)\right]
$$




$$
\begin{array}{ll}
\text { s.t } & t \tilde{c}_{1} \leq b_{o 1} k_{o 1}+b_{1} \tilde{\mu} k_{o 2} \\
& (1-t) \tilde{c}_{2}=b_{o 2}(1-\tilde{\mu}) k_{o 2}+\tilde{b}_{12}\left[b_{o 1} k_{o 1}+b_{1} \tilde{\mu} k_{o 2}-t \tilde{c}_{1}\right] \\
& \tilde{c}_{1} \tilde{b}_{12} \leq \tilde{c}_{2} \\
& \tilde{\mu} \leq 1 \\
& \tilde{c}_{i} \geq 0 \\
& \tilde{\mu} \geq 0
\end{array}
$$

The Kuhn-Tucker conditions are:

$$
\begin{aligned}
t c_{1}^{-\gamma}-\lambda_{1} t+t b_{12} \lambda_{2}-\lambda_{3} b_{12}=0 & \text { if } c_{1}>0 \\
(1-t) c_{2}^{-\gamma}+(1-t) \lambda_{2}+\lambda_{3}=0 & \text { if } c_{2}>0 \\
k_{o 2} b_{1} \lambda_{1}-k_{o 2}\left(b_{1} b_{12}-b_{o 2}\right) \lambda_{2}-\lambda_{3}=0 & \text { if } \mu>0 \\
b_{o 1} k_{o 1}+\mu k_{o 2} b_{1}-t c_{1}=0 & \text { if } \lambda_{1}>0 \\
(1-t) c_{2}-(1-\mu) b_{o 2} k_{o 2}-\left[\mu k_{o 2} b_{1}+b_{o 1} k_{o 1}-t c_{1}\right] b_{12}=0 & \forall \lambda_{2} \\
c_{2}-b_{12} c_{1}=0 & \text { if } \lambda_{3}>0 \\
1-\mu=0 & \text { if } \lambda_{4}>0
\end{aligned}
$$

The following cases may be considered:

CASE A: $\left(\lambda_{1}>0 ; \lambda_{3}=0 ; \mu^{*}=0\right)$

In this case the optimal solution corresponds to the first best solution given by equations [5] and [6](where $\rho_{1}=1$ and $\left.\rho_{2}=0\right)^{16}$ :

$$
\tilde{c}_{1}^{*}=\frac{b_{o 1} k_{o 1}}{t} \quad \tilde{c}_{2}^{*}=\frac{b_{o 2} k_{o 2}}{1-t}
$$

This solution is incentive compatible as long as $c_{1} b_{12} \leq c_{2}$. Substituting the optimal consumption levels in the above expression, the following condition for this case to hold is obtain, that is, $b_{12} \leq b_{2}^{*}=\frac{t b_{02} k_{02}}{(1-t) b_{01} k_{o 1}}$

Similarly, it is assumed $\mu^{*}=0$, that means $\frac{\partial L}{\partial \mu} \leq 0$

$$
\frac{\partial L}{\partial \mu} \leq b_{1} \lambda_{1}-b_{1} b_{12} \lambda_{2}+b_{o 2} \lambda_{2} \leq 0
$$

Substituting $\lambda_{1}=c_{1}^{-\gamma}+b_{12} \lambda_{2}$ and $\lambda_{2}=-c_{2}^{-\gamma}$ in the above expression, the condition on $b_{1}$, for this case to hold is obtained: $b_{1} \leq \bar{b}_{1}=\frac{\left[\frac{b_{01} k_{o 2}}{-t}\right]^{-\gamma} b_{o 2}}{\left[\frac{b_{01} k_{01}}{t}\right]^{-\gamma}}$.

\footnotetext{
${ }^{16}$ Notice that in this case $b_{\lim }=\infty$.
} 
CASE B: $\left(\lambda_{1}=0 ; \lambda_{3}>0 ; \mu^{*}=0\right)$

The optimal solution to this case yields:

$$
\tilde{c}_{1}^{*}=\frac{b_{o 2} k_{o 2}}{\tilde{b}_{12}}+b_{o 1} k_{o 1} \quad \tilde{c}_{2}^{*}=b_{o 2} k_{o 2} \tilde{b}_{12}+b_{o 1} k_{o 1}
$$

Similarly, this case is satisfied when $t c_{1} \leq b_{o 1} k_{o 1}$. Substituting the value of $c_{1}^{*}$ in the above expression the condition for this case to hold is obtained, that is: $b_{12} \geq b_{2}^{*}$.

Finally, it is also assumed $\mu^{*}=0$, so the same condition as in the previous case would be obtained.

CASE C: $\left(\lambda_{1}>0 ; \lambda_{3}=0 ; \mu^{*}>0\right)$

The optimal solution in this case yields:

$$
\tilde{c}_{1}^{*}=\frac{\left(b_{o 1} k_{o 1}+k_{o 2} b_{1}\right) b_{o 2}}{t b_{o 2}+(1-t) b_{1}\left[\frac{b_{o 2}}{b_{1}}\right]^{1 / \gamma}} \quad \tilde{c}_{2}^{*}=\left[\frac{b_{o 2}}{b_{1}}\right]^{1 / \gamma} c_{1}^{*}
$$

and $\mu^{*}=\frac{t c_{1}^{*}-b_{o 1} k_{o 1}}{b_{1} k_{o 2}}$

This case is satisfied as long as $c_{1} b_{12} \leq c_{2}$. Substituting the optimal consumption levels in the above expression, the condition for this case to hold is obtained, i.e, $b_{12} \leq b_{2}^{* *}=\left[\frac{b_{o 2}}{b_{1}}\right]^{1 / \gamma}$

CASE D: $\left(\lambda_{1}>0, \lambda_{3}>0, \mu^{*}>0\right)$

Finally, the optimal solution in this case is:

$$
\tilde{c}_{1}^{*}=\frac{b_{o 1} k_{o 1} \frac{b_{o 2}}{b_{1}}+b_{o 2} k_{o 2}}{t\left[\frac{b_{o 2}}{b_{1}}\right]+(1-t) \tilde{b}_{12}} \quad \tilde{c}_{2}^{*}=\tilde{b}_{12} c_{1}^{*}
$$

and $\mu^{*}=\frac{t c_{1}^{*}-b_{o 1} k_{o 1}}{b_{1} k_{o 2}}$

This case is satisfied if $b_{12} \in\left(b_{2}^{* *}, b_{2}^{*}\right)$.

The limit value $b_{2}^{*}$ is obtained by equalizing $\mu^{*}=0$, in the above solution.

\section{Second-step Solution:}

Finally, the optimal levels of the initial investments are obtained as a solution to the following problem:

$$
\max _{k_{o 1}, k_{o 2}}\left[\begin{array}{cc}
\int_{b_{\min }}^{b_{2}^{*}} U^{*(A)} f\left(b_{12}\right) d b_{12}+\int_{b_{2}^{*}}^{b_{\max }} U^{*(B)} f\left(b_{12}\right) d b_{12} & \text { if } b_{1} \leq \bar{b}_{1} \\
\int_{b_{\min }}^{b_{2}^{* *}} U^{*(C)} f\left(b_{12}\right) d b_{12}+\int_{b_{2}^{* *}}^{b_{2}^{*}} U^{*(D)} f\left(b_{12}\right) d b_{12} & \\
+\int_{b_{2}^{*}}^{b_{\max }} U^{*(B)} f\left(b_{12}\right) d b_{12} & \text { if } b_{1}>\bar{b}_{1}
\end{array}\right]
$$




\section{NOTE ON CONTRIBUTOR/ACKNOWLEDGMENT}

Margarita Samartín is with Universidad Carlos III de Madrid.

This research is partially funded by the Spanish Ministry of Education and Culture, project: PB97-0089, DGES. The author owes special thanks to Sudipto Bhattacharya, Heracles Polemarchakis, Ron Anderson, Henri Sneessens, Marie Odile Yanelle, Sandro Brusco and an anonymous referee for their very helpful comments in earlier versions of this paper. 